\title{
In-Situ Vibrational Spectroscopic Studies on Model Catalyst Surfaces at Elevated Pressures
}

\author{
Emrah Ozensoy • Evgeny I. Vovk
}

Published online: 30 July 2013

(c) Springer Science+Business Media New York 2013

\begin{abstract}
Elucidation of complex heterogeneous catalytic mechanisms at the molecular level is a challenging task due to the complex electronic structure and the topology of catalyst surfaces. Heterogeneous catalyst surfaces are often quite dynamic and readily undergo significant alterations under working conditions. Thus, monitoring the surface chemistry of heterogeneous catalysts under industrially relevant conditions such as elevated temperatures and pressures requires dedicated in situ spectroscopy methods. Due to their photons-in, photons-out nature, vibrational spectroscopic techniques offer a very powerful and a versatile experimental tool box, allowing real-time investigation of working catalyst surfaces at elevated pressures. Infrared reflection absorption spectroscopy (IRAS or IRRAS), polarization modulation-IRAS and sum frequency generation techniques reveal valuable surface chemical information at the molecular level, particularly when they are applied to atomically well-defined planar model catalyst surfaces such as single crystals or ultrathin films. In this review article, recent state of the art applications of in situ surface vibrational spectroscopy will be presented with a particular focus on elevated pressure adsorption of
\end{abstract}

This article is dedicated to late D. Wayne Goodman, my Ph.D. advisor, an outstandingly brilliant scientist, a truly inspirational character and a great scientific role model (E.O.).

E. Ozensoy $(\varangle) \cdot$ E. I. Vovk

Department of Chemistry, Bilkent University,

06800 Ankara, Turkey

e-mail: ozensoy@fen.bilkent.edu.tr

E. I. Vovk

Boreskov Institute of Catalysis, 630090 Novosibirsk,

Russian Federation probe molecules (e.g. $\mathrm{CO}, \mathrm{NO}, \mathrm{O}_{2}, \mathrm{H}_{2}, \mathrm{CH}_{3} \mathrm{OH}$ ) on monometallic and bimetallic transition metal surfaces (e.g. $\mathrm{Pt}, \mathrm{Pd}, \mathrm{Rh}, \mathrm{Ru}, \mathrm{Au}, \mathrm{Co}, \mathrm{PdZn}, \mathrm{AuPd}, \mathrm{CuPt}$, etc.). Furthermore, case studies involving elevated pressure carbon monoxide oxidation, CO hydrogenation, Fischer-Tropsch, methanol decomposition/partial oxidation and methanol steam reforming reactions on single crystal platinum group metal surfaces will be provided. These examples will be exploited in order to demonstrate the capabilities, opportunities and the existing challenges associated with the in situ vibrational spectroscopic analysis of heterogeneous catalytic reactions on model catalyst surfaces at elevated pressures.

Keywords PM-IRAS $\cdot \mathrm{SFG} \cdot \mathrm{FTIR} \cdot \mathrm{CO} \cdot \mathrm{NO} \cdot$ In-situ

\section{Introduction}

Achieving ultimate control over catalytic activity and selectivity in heterogeneous catalytic reactions demands addressing not only the sophisticated macroscopic engineering problems such as reactor design and mass/heat transfer but it also requires tackling the fundamental scientific challenges at the molecular level. Thus, a detailed understanding of the complex morphology, chemical composition and electronic structure of the heterogeneous catalytic surfaces is the key for designing new catalytic processes which are efficient, sustainable, renewable and environmentally friendly. Unfortunately, most of the conventional spectroscopic or diffraction techniques that are commonly used for routine material characterization fail to provide a truly surface-sensitive description of the catalyst surfaces at the molecular level. 
This important drawback stimulated the emergence of a multitude of novel surface-sensitive characterization techniques, such as X-ray photoelectron spectroscopy (XPS), low energy electron diffraction (LEED), scanning tunneling microscopy (STM), low energy ion scattering (LEIS), metastable impact electron spectroscopy (MIES), high resolution electron energy loss spectroscopy (HREELS) and many others [1]. However, most of these techniques rely on electrons or ions having extremely short elevatedpressure mean free paths, rendering their application to working catalysts difficult. Although some of the techniques such as XPS [2-4] and STM [5-8] evolved over time to handle elevated pressures and temperatures, majority of these surface-sensitive techniques remained to be strictly ultra-high vacuum (UHV) based approaches for model catalyst characterization, which is commonly referred as the "pressure gap" problem (Scheme 1) [9]. Furthermore, in situ XPS and STM techniques often fail to provide accurate or unambiguous information about the nature of the surface functional-groups which are taking part in the catalytic reaction.

On the other hand, infrared reflection absorption spectroscopy (IRAS, IRRAS or RAIRS) [10, 11], polarization modulation infrared reflection absorption spectroscopy (PM-IRAS or PM-IRRAS) [12-26] and sum frequency generation (SFG) [27-32] are essentially photon-based surface-sensitive spectroscopic techniques which are significantly less prone to the presence of a high pressure gas phase environment surrounding the catalytic surface of interest. These techniques are extremely beneficial as they have the potential to provide a comprehensive description of the surface functional groups existing on the catalyst surface under working conditions. Thus, such surfacesensitive vibrational spectroscopic techniques provide invaluable opportunities for studying heterogeneous catalysis in real time under industrially relevant operational conditions and on complex model catalyst surfaces that can help bridge the so called "materials gap" (Scheme 1) [9]. Hence, in situ studies reveal new opportunities for obtaining molecular level insight about catalytic reaction mechanisms and structure-reactivity relationships.

Along these lines, in this review article, recent applications of state of the art in situ surface vibrational spectroscopic studies performed in the last decade in D. Wayne Goodman research group as well as other research groups are presented in order to demonstrate the capabilities, opportunities and the existing challenges associated with the in situ vibrational spectroscopic analysis of heterogeneous catalytic reactions on model catalyst surfaces at elevated pressures. This review is organized as follows: Sect. 2 gives a brief description of the experimental techniques relevant to the discussion. Sections 3.1.1 and 3.1.2 provide a discussion on the $\mathrm{CO}$ adsorption and $\mathrm{NO}$ adsorption, respectively which is followed by studies on $\mathrm{CO}+\mathrm{NO}$ reaction (Sects. 3.2.1 and 3.2.2). Section 3.2.3 focuses on high-pressure $\mathrm{CO}+\mathrm{H}_{2}$ interactions which also includes studies relevant to Fischer-Tropsch chemistry. Section 3.2.4. details the mechanistic aspects of $\mathrm{CO}$ oxidation on platinum group metal (PGM) surfaces at elevated pressures. Section 3.2.5 deals with the catalytic methanol
Scheme 1 Bridging the "Pressure" and "Materials" gaps between surface science and catalysis

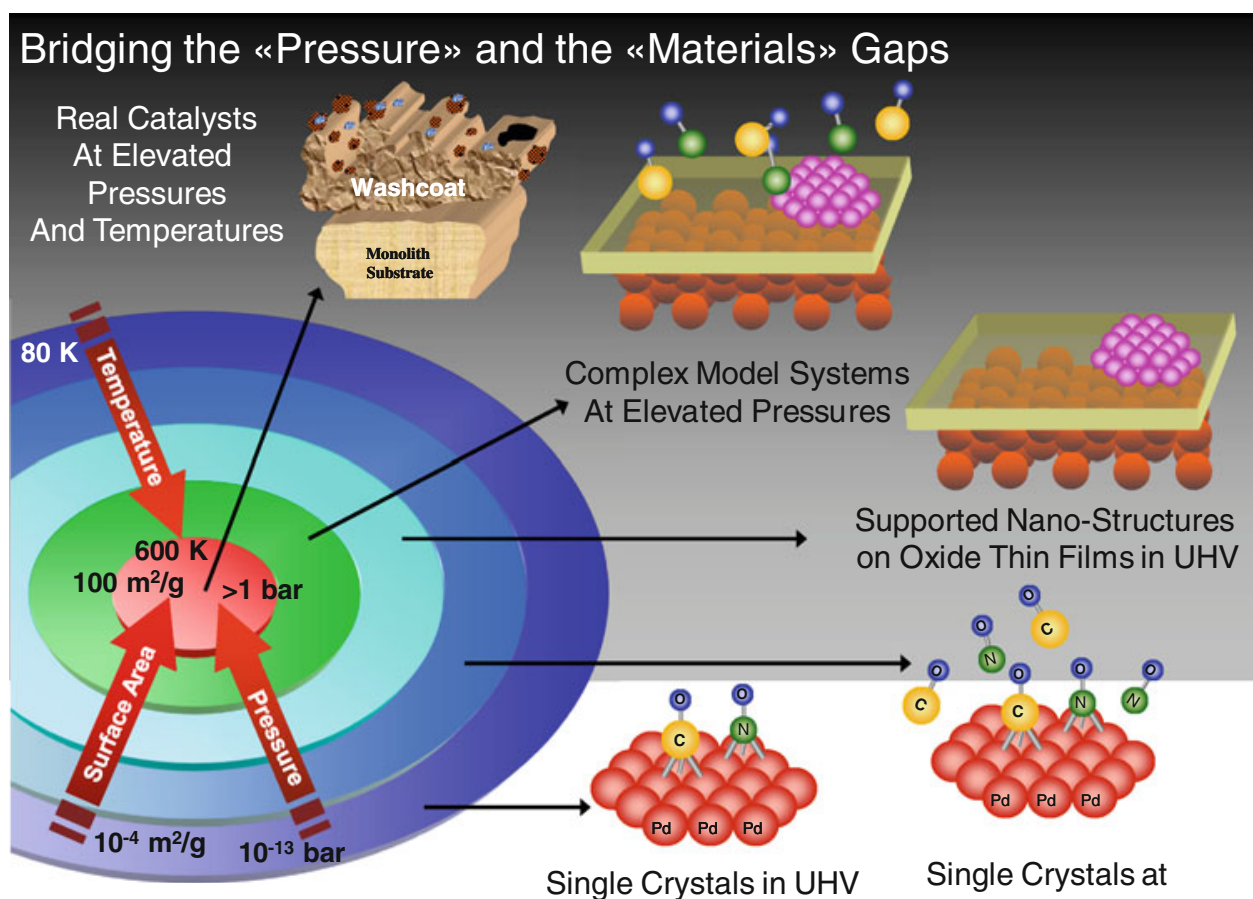

Elevated Pressures 
reactions on Pd and PdZn based model catalysts. Finally, an overall assessment of the reviewed work as well as a brief outlook is provided in Sect. 4.

\section{Experimental}

Experiments that are discussed in this review have been performed in various custom-design multi-technique UHV surface analysis chambers, which are typically equipped with elevated pressure reactors that enable the use of in situ vibrational spectroscopic techniques (in the high-pressure mode) as well as other conventional surface analysis techniques (in the UHV mode). Further experimental details regarding the experimental hardware and procedures can be found in the relevant references cited in the text. Case studies that will be discussed in this review primarily utilize three main surface vibrational spectroscopic techniques namely, IRAS, PM-IRAS and SFG [10-34]. As the main emphasis of the current text is the applications of in situ vibrational spectroscopies, detailed operational principles and the theoretical background associated with these spectroscopic techniques will not be discussed here. Instead, only brief descriptions of these techniques will be provided. For a more comprehensive discussion about these techniques, reader is referred to the cited references in the text and references therein.

Briefly, PM-IRAS [12-16] is a versatile in situ spectroscopic technique that yields information about the surface species at solid-liquid or gas-solid interfaces by effectively removing the contribution from the background gas or liquid phase (Fig. 1). Elimination of the vibrational contribution from gas-phase species is vital for the in situ analysis of solid-gas interfaces, as these species overwhelm the smaller IR signal corresponding to the adsorbed states. The basic operational principle of the PM-IRAS technique relies on the modulation (Fig. 1b) of a linearly polarized IR beam by dividing the linearly polarized light into an s-polarized beam (i.e. parallel to the surface of the sample), and a p-polarized beam (i.e. perpendicular to the sample surface). According to the surface selection rules of IR radiation reflected from electrically conducting surfaces (Fig. 1c), [10] species adsorbed on a metal surface can only absorb p-polarized IR light, while any molecule in the isotropic gaseous or liquid phase can absorb both p- and s-polarized IR radiation. Thus, if p-polarized IR reflection signal is subtracted from the s-polarized signal and normalized by the total intensity of both p-and s-polarized IR (a)

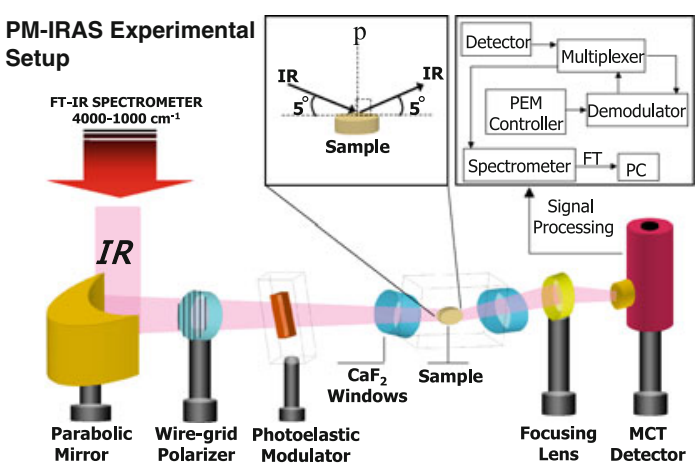

(c)

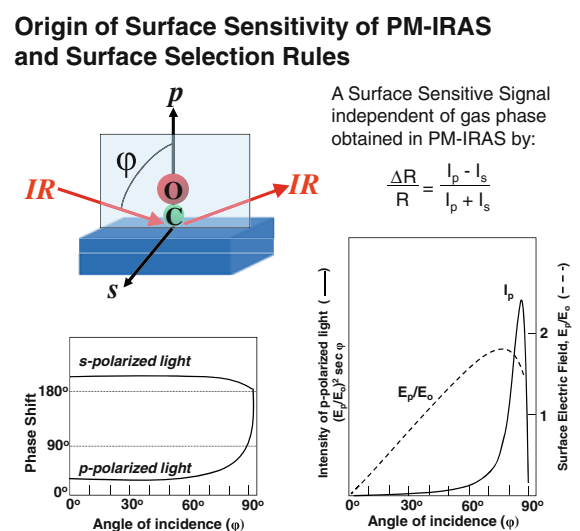

(b)

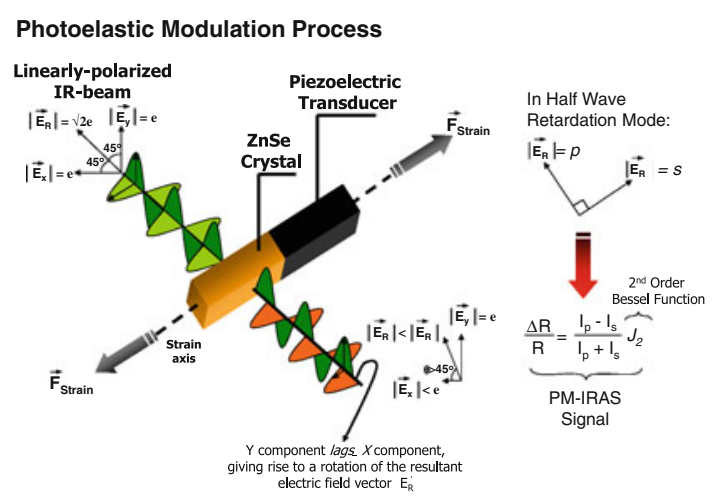

(d)

PM-IRAS Data Acquisition
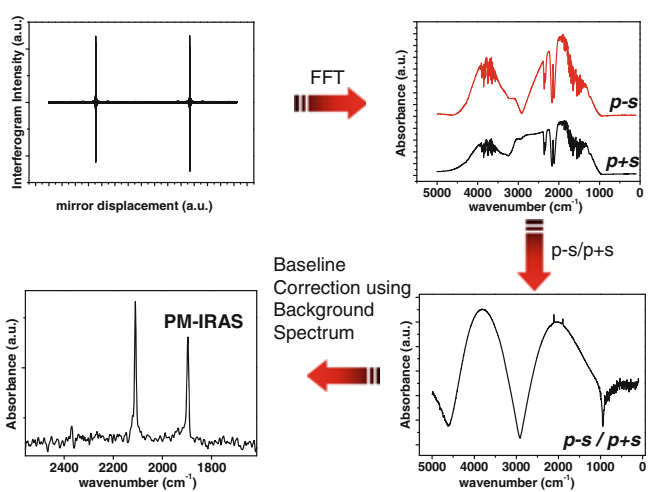

Fig. 1 Basic operational principles of PM-IRAS [17, 18]. a Experimental setup, b description of the PM process, $\mathbf{c}$ origin of PM-IRAS selection rules and surface sensitivity, $\mathbf{d}$ typical stages of the PM-IRAS data acquisition process (see text for details) 
reflection beams through a virtual double-beam spectroscopic approach, a normalized surface specific IR absorption signal, practically independent of the environmental conditions, can be obtained (Fig. 1d).

On the other hand, vibrational SFG technique utilizes a second-order nonlinear optical process in which two light waves at different frequencies interact in a medium characterized by a nonlinear susceptibility tensor $\chi^{(2)}$ resulting in a wave corresponding to the sum of the frequencies of the interacting waves $[28,29,35]$. In order to obtain a SFG vibrational spectrum of adsorbates on a planar model catalyst, two picosecond laser pulses are spatially and temporally overlapped on the sample (Fig. 2) where one of the input laser pulses is in the visible frequency range having a fixed frequency $\left(\omega_{\mathrm{vis}}\right)$, and the second laser pulse has a variable (tunable) frequency in the mid-IR region $\left(\omega_{\mathrm{IR}}\right)$. Tuning the IR beam to the oscillatory frequency of the adsorbate results in a vibrational transition from the ground state to an excited state accompanied by a transition to a higher-energy virtual state through an anti-Stokes Raman process by the visible beam. Upon relaxation of the excited virtual state, a signal is generated with a frequency in the visible spectral region corresponding to the sum of the frequencies of the input laser beams $\left(\omega_{\mathrm{SFG}}=\omega_{\mathrm{IR}}+\omega_{\mathrm{vis}}\right)$. Thus, a complete vibrational spectrum can be obtained by plotting the frequency of the

(a)

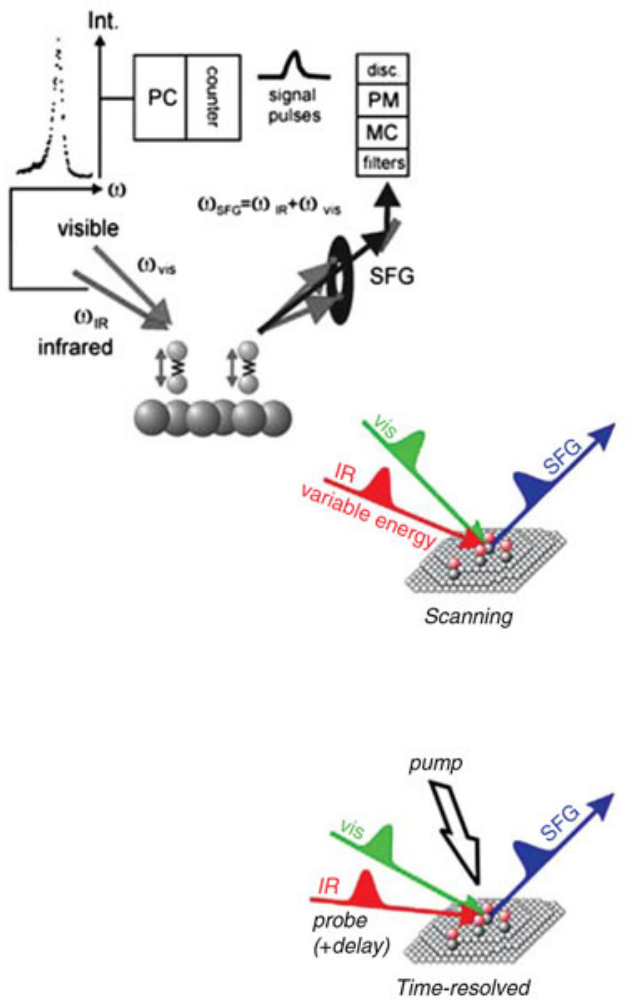

input IR beam as a function of the SFG signal intensity. Selection rules associated with the SFG technique render this method a truly surface sensitive technique. In order to be SFG active, the vibrational mode of interest should be both IR and Raman active. This means SFG signal can be detected for the adsorbates at the gas/solid or liquid/solid interfaces where inversion symmetry is broken. However SFG is not allowed for the media having inversion symmetry such as bulk solids, liquids and gases [35].

\section{Results and Discussion}

3.1 Adsorption of Simple Probe Molecules on Model Catalyst Surfaces at Elevated Pressures

\subsubsection{CO Adsorption}

3.1.1.1 CO Adsorption on Pd(111) and Pd(100) Some of the early seminal vibrational spectroscopic studies on elevated-pressure $\mathrm{CO}$ adsorption on Pd single crystal surfaces were performed by Kuhn et al. [36] where they investigated $\mathrm{CO} / \mathrm{Pd}(111)$ adsorption system within $10^{-6}-10.0$ Torr via IRAS technique (Fig. 3a). A decade later, by utilizing the powerful in situ capabilities of the PM-IRAS technique,

(c)

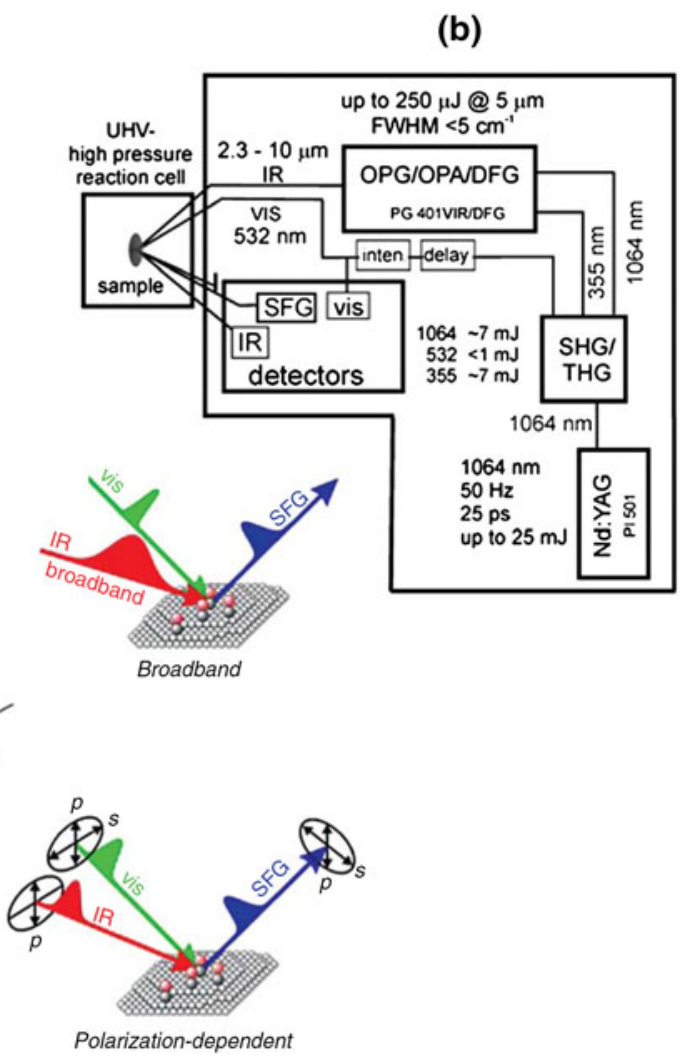

Fig. 2 Basic operational principles of SFG. a IR-vis SFG process [29], b description of an SFG spectrometer based on a Nd:YAG picosecond laser system [29], c various modes of operation for SFG: scanning, broadband, pump-probe and polarization-dependent operational modes [35] 
similar experiments were extended to even higher $\mathrm{CO}$ partial pressures (i.e. $\mathrm{P}_{\mathrm{CO}}=450$ Torr) by Ozensoy et al. [19] (Fig. 3b) and shortly after by Stacchiola et al. [37]. In conjunction with the high-resolution STM results on the $\mathrm{CO} / \mathrm{Pd}(111)$ system [38], it has been found [19] that CO forms identical set of ordered overlayers between $10^{-6}$ 450.0 Torr on the clean $\operatorname{Pd}(111)$ substrate as a function coverage, without any indications for the presence of adsorbate induced surface reconstructions or any unusual high-pressure phenomena. These results clearly indicated that $\mathrm{CO} / \mathrm{Pd}(111)$ is a uniquely interesting adsorption system, where the nature of the coverage-dependent $\mathrm{CO} /$ $\operatorname{Pd}(111)$ overlayers are unusually invariant within nine orders of magnitude in $\mathrm{CO}$ pressure where similar ordered overlayers are observed at various coverages under different pressure-temperature conditions. These studies revealed that at a $\mathrm{CO}$ coverage of $\theta_{\mathrm{CO}}=0.33 \mathrm{ML}$ $(\mathrm{ML}=$ monolayer $)$ a $(\sqrt{ } 3 \times \sqrt{ } 3) \mathrm{R} 30^{\circ}-1 \mathrm{CO}$ structure is observed (Fig. 3c) where $\mathrm{CO}$ resides primarily on threefold hollow sites revealing a $\mathrm{C}-\mathrm{O}$ vibrational frequency of $\sim 1,850 \mathrm{~cm}^{-1}$. Upon increasing the $\mathrm{CO}$ coverage to $\theta_{\mathrm{CO}}=0.50 \mathrm{ML}$, two coexisting $\mathrm{c}(4 \times 2)-2 \mathrm{CO}$ phases appear in which $\mathrm{CO}$ is located on either the bridging sites or threefold hollow sites, yielding a vibrational signal at $\sim 1,920 \mathrm{~cm}^{-1}$. For $\theta_{\mathrm{CO}}=0.50-0.75 \mathrm{ML}$, various complex overlayer structures are formed with a $\mathrm{CO}$ vibrational band near $1,965 \mathrm{~cm}^{-1}$. Finally, the saturation $\mathrm{CO}$ coverage is obtained at $\theta_{\mathrm{CO}}=0.75 \mathrm{ML}$, revealing a $(2 \times 2)-3 \mathrm{CO}$ structure where $\mathrm{CO}$ is located on both atop and threefold hollow sites corresponding to vibrational features at 2,110 and $1,895 \mathrm{~cm}^{-1}$, respectively.

These PM-IRAS experiments were also in perfect agreement with the SFG experiments performed on the $\mathrm{CO} / \mathrm{Pd}(111)$ system at elevated pressures yielding results consistent with the ones discussed above [39]. It is worth mentioning that special attention has to paid for cleaning the adsorbate gas (in this case $\mathrm{CO}$ ) during the elevated pressure experiments (which can easily be achieved by keeping the $\mathrm{CO}$ container in a liquid nitrogen reservoir at $77 \mathrm{~K}$ throughout the experiments) in order to prevent accumulation of unwanted contaminations such as $\mathrm{H}_{2} \mathrm{O}$ or nickel/iron carbonyls (originating from the gas tank) on the catalyst surface which can be misinterpreted as new "highpressure" species [40]. Furthermore, SFG studies [40] on the $\mathrm{CO}$ adsorption on the defect-rich $\operatorname{Pd}(111)$ surfaces revealed the presence of bridging $\mathrm{CO}$ species at low coverages with a vibrational signature at $1,980-1,990 \mathrm{~cm}^{-1}$ which disappeared at high coverages yielding a saturation $\mathrm{CO}$ overlayer similar to that of the clean $\operatorname{Pd}(111)$ surface. Independent PM-IRAS [20] and SFG [41, 42] studies revealed that $\mathrm{CO}$ dissociation was not observed neither on clean nor on defect-rich $\operatorname{Pd}(111)$.

$\mathrm{CO}$ adsorption on the $\mathrm{Pd}(100)$ single crystal surface was also investigated by Szanyi et al. [43] within $10^{-6}-1.0$ Torr via IRAS technique where the presence of only bridging CO was observed for all coverages $\left(0 \mathrm{ML}<\theta_{\mathrm{CO}}<0.8\right.$ ML) with a $\mathrm{CO}$ vibrational frequency ranging from 1,895 to $1,995 \mathrm{~cm}^{-1}$.

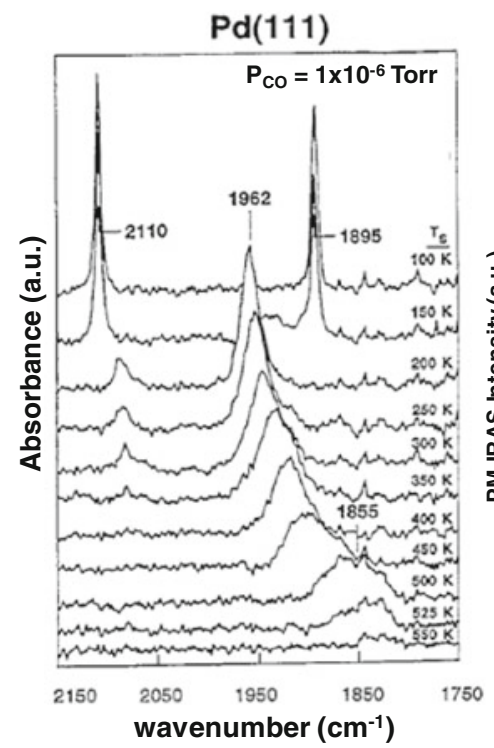

(a)

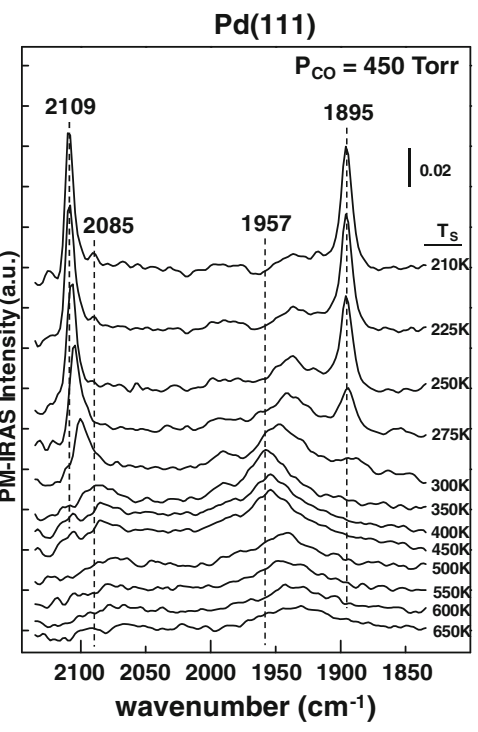

(b)

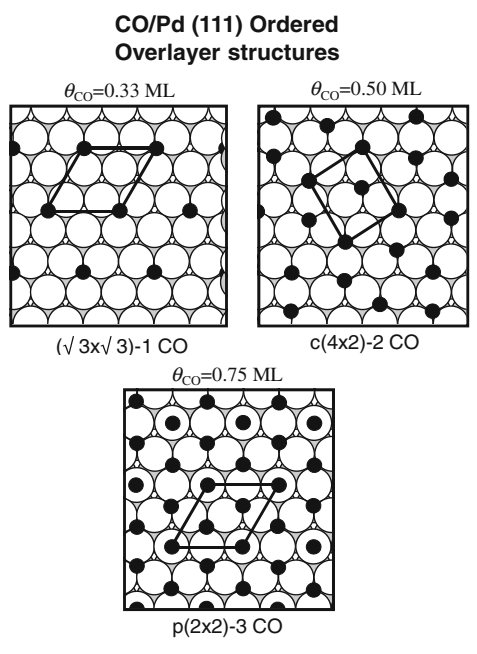

(c)
Fig. 3 a In-situ IRAS data for $\mathrm{CO}$ adsorption on $\mathrm{Pd}(111)$ at $\mathrm{P}_{\mathrm{CO}}=1 \times 10^{-6}$ Torr [36]; $\mathbf{b}$ in situ PM-IRAS data for $\mathrm{CO}$ adsorption on $\mathrm{Pd}(111)$ at $\mathrm{P}_{\mathrm{CO}}=450$ Torr [19]; c ordered $\mathrm{CO}$ overlayer structures on the $\operatorname{Pd}(111)$ single crystal surface. Note that an alternative $\mathrm{c}(4 \times 2)-2 \mathrm{CO}$ structure containing only bridging $\mathrm{CO}$ molecules is also possible for $\theta_{\mathrm{CO}}=0.50 \mathrm{ML}$ 
3.1.1.2 CO adsorption on Pd Nanoparticles Deposited on Planar Metal Oxide Ultrathin Films Grown on Metal Substrates $\left(\mathrm{CO} / \mathrm{Pd} / \mathrm{SiO}_{2} / \mathrm{Mo}(112)\right.$ and $\left.\mathrm{CO} / \mathrm{Pd}_{\mathrm{Al}} \mathrm{A}_{2} \mathrm{O}_{3} / \mathrm{Ni}(110)\right)$ Elevated pressure $\mathrm{CO}$ adsorption experiments on $\mathrm{Pd}$ single crystals were also extended to more complex model catalyst surfaces such as metal nanoparticles deposited on metal oxide ultrathin films. These structurally complex model catalyst systems enable investigation of important catalytic phenomena associated with the presence of 3D nanostructures revealing different types of surface defects (e.g. coordinatively unsaturated surface sites, point defects, edges, steps, kinks, etc.) which is crucial for efforts towards bridging the "materials gap" (Scheme 1). Such model catalyst surfaces are also suitable for studying particle size effects and structure sensitivity of catalytic reactions. There exists numerous UHV surface science studies on metal nanoparticles deposited on ultrathin films [44, 45] however, in situ investigation of such surfaces under elevated pressures has been viable only recently.

The first elevated-pressure PM-IRAS study on a metal nanoparticle system deposited on a crystalline ultrathin metal oxide film grown on a metallic substrate was performed by Ozensoy et al. [20] where they investigated CO adsorption on the $\mathrm{Pd}(\sim 3.5 \mathrm{~nm}) / \mathrm{SiO}_{2} / \mathrm{Mo}(112)$ model catalyst surface at 185 mbar (Fig. 4). Comparison of the PMIRAS data given in Fig. 4a with former UHV studies on $\mathrm{CO} / \mathrm{Pd}(111)$ [36] and $\mathrm{CO} / \mathrm{Pd}(100)$ [40] suggested that the silica supported Pd nanoparticles predominantly exhibited $\langle 111\rangle$ facets with a minor contribution from $\langle 100\rangle$ facets. Along these lines, $2,089 \mathrm{~cm}^{-1}$ was attributed to CO species adsorbed on the atop sites of the $\langle 111\rangle$ facets of the Pd nanoclusters while the shoulder features located at 2,071 and $2,045 \mathrm{~cm}^{-1}$ were assigned to $\mathrm{CO}$ residing on defect sites of the Pd nanoparticles such as steps or edges. Furthermore, the vibrational features located at 1,957 and $1,895 \mathrm{~cm}^{-1}$ in Fig. $4 \mathrm{a}$ are associated with the CO molecules occupying bridging and threefold hollow sites of the $\langle 111\rangle$ facets, respectively. Annealing-cooling cycles performed in the presence of $\mathrm{CO}$ gas phase on these two different model catalyst surfaces suggested that although such a treatment leads to the $\mathrm{CO}$ dissociation and the accumulation of carbonaceous species on the silica-supported Pd nanoparticles at elevated pressures, evident by the irreversible attenuation of the IR signal intensities and the existence of C-deposit (i.e. $271 \mathrm{eV}$ signal) in the Auger electron spectra (AES) obtained after thermal cycles (Fig. 4a), CO adsorption on $\mathrm{Pd}(111)$ is perfectly reversible even at elevated pressures without any indication of $\mathrm{CO}$ dissociation [20]. Furthermore, it was argued that CO molecules residing on the bridging or atop sites of the steps of the Pd nanoclusters were likely to be responsible for $\mathrm{CO}$ dissociation. It was proposed that after the initial dissociation of $\mathrm{CO}$ on the defect sites, atomic $\mathrm{C}$ and $\mathrm{O}$ diffuse to the neighboring atop $\left(2,089\right.$ and $\left.2,071 \mathrm{~cm}^{-1}\right)$ and bridging sites $\left(2,045 \mathrm{~cm}^{-1}\right)$ in close proximity of the active sites. Attenuation of the broad vibrational band at $2,089 \mathrm{~cm}^{-1}$ then occurs. In a second anneal-cool cycle, further $\mathrm{CO}$ dissociation results in the spill-over of atomic $\mathrm{C}$ and $\mathrm{O}$ over the entire Pd cluster, resulting in nonselective attenuation of all vibrational features and to complete poisoning of the Pd clusters [20]. It is worth mentioning that CO dissociation over Pd surfaces is still a rather controversial issue where there exist studies in the literature reporting the dissolution of atomic $\mathrm{C}$ in the $\mathrm{Pd}(110)$ single crystal lattice and hence obscuring the detection of the dissociation process [46], as well as other studies on $\mathrm{Pd} / \mathrm{Al}_{2} \mathrm{O}_{3}$ high surface area materials ruling out $\mathrm{CO}$ dissociation over supported Pd nanoparticles [47].

Elevated-pressure $\mathrm{CO}$ adsorption on supported $\mathrm{Pd}$ nanoparticles deposited on alumina ultrathin films grown on $\mathrm{NiAl}(110)$ substrate was also studied comprehensively via SFG technique [39, 40, 48-50].For instance, influence of the particle size on the nature of the Pd adsorption sites existing on the supported Pd nanoparticles were demonstrated (Fig. 5) [48] where it was shown that the CO molecules prefer to adsorb predominantly on the atop sites on the smaller $(3.5 \mathrm{~nm})$ and defective/rough Pd particles for low CO coverages (Fig. 5a), while on the bigger $(6 \mathrm{~nm})$ $\mathrm{Pd}$ particles exhibiting larger planar facets, $\mathrm{CO}$ is also found to adsorb on bridging sites (Fig. 5b). Upon increasing the surface $\mathrm{CO}$ coverage with increasing $\mathrm{CO}$ pressure, both atop and bridging sites are populated on both surfaces although relative population of atop sites are still higher for smaller Pd particles. It is worth mentioning that these results are in good agreement with former UHV studies performed on similar systems [21].

3.1.1.3 CO/Pt(111) CO adsorption on $\operatorname{Pt}(111)$ is one of the most extensively studied surface science systems in the literature which has been investigated via a large variety of surface science tools. At a CO coverage of $0.5 \mathrm{ML}$, an ordered $\mathrm{c}(4 \times 2)-2 \mathrm{CO}$ overlayer is formed where $\mathrm{CO}$ was found to adsorb on both atop and bridging sites (Fig. 6) [51-54]. For higher CO surface coverages two different compressed $\mathrm{CO}$ overlayers have been reported, namely the commensurate $(7 \times \sqrt{3})$ rect-10CO at $\theta_{\mathrm{CO}}=0.71 \mathrm{ML}$ [55] and the hexagonal Moiré structures $((\sqrt{ } 19 \times$ $\sqrt{ }$ 19)R23.4-13CO) at $\theta_{\mathrm{CO}}=0.68$ (Fig. 6) [55].

Earlier experiments performed on the $\mathrm{CO} / \mathrm{Pt}(111)$ adsorption system at elevated pressures have been reviewed by Rupprechter [29]. More recently, Carrasco et al. [53] combined a detailed set of PM-IRAS and SFG experiments on this system within $10^{-7}-100$ mbar (Fig. 7) and provided a comprehensive description of the ordered high coverage (compressed) $\mathrm{CO}$ overlayers formed on Pt(111). PM-IRAS results in this work (Fig. 7a) revealed 
Fig. 4 In-situ PM-IRAS data for elevated-pressure $\mathrm{CO}$ adsorption on $\mathbf{a} \operatorname{Pd}(\sim 3.5 \mathrm{~nm}) /$ $\mathrm{SiO}_{2} / \mathrm{Mo}(112)$ and b $\mathrm{Pd}(111)$ model catalyst surfaces. Top spectra in each panel show the initial $\mathrm{CO}$ adsorption on the clean model catalyst surfaces while the remaining spectra were obtained after annealingcooling cycles in the presence of the $\mathrm{CO}$ gas phase. Inset in (a) shows the $\mathrm{C}$ accumulation in AES after multiple annealingcooling cycles due to the $\mathrm{CO}$ dissociation on the silica supported Pd particles, while $\mathrm{CO}$ dissociation was not observed on $\operatorname{Pd}(111)$ upon a similar treatment [20]

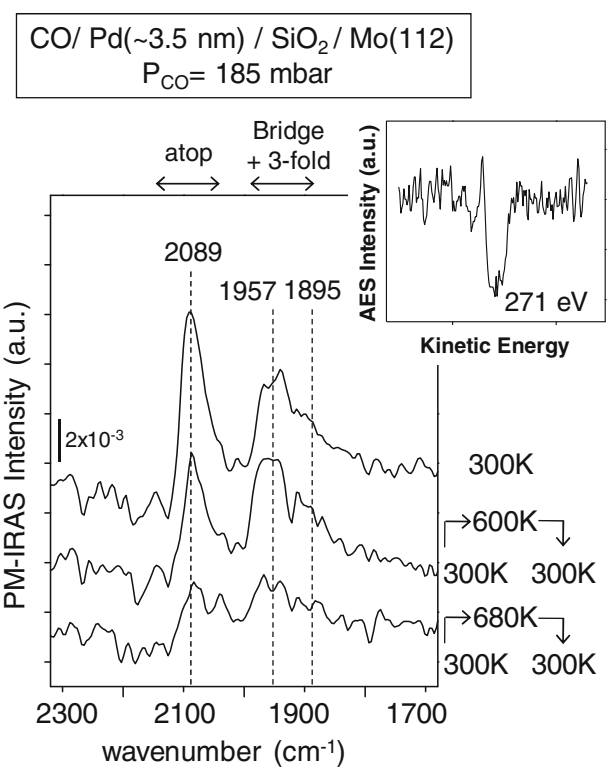

(a)

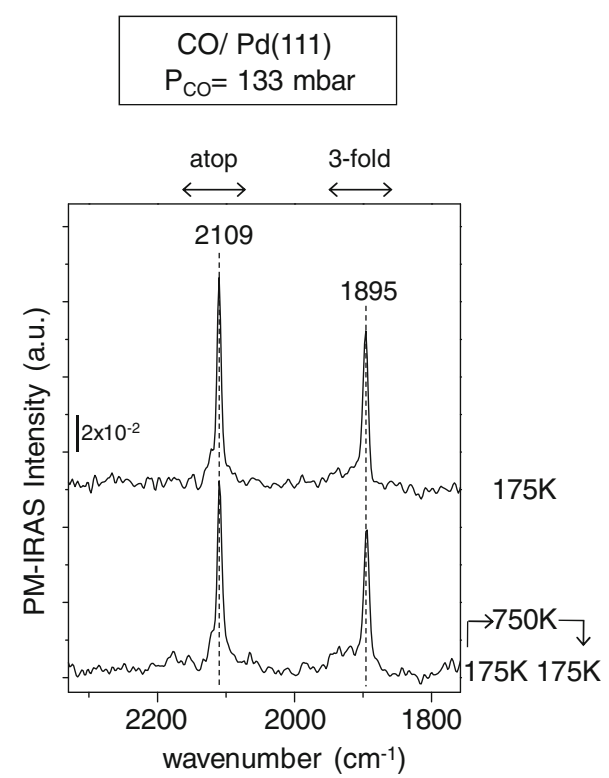

(b)

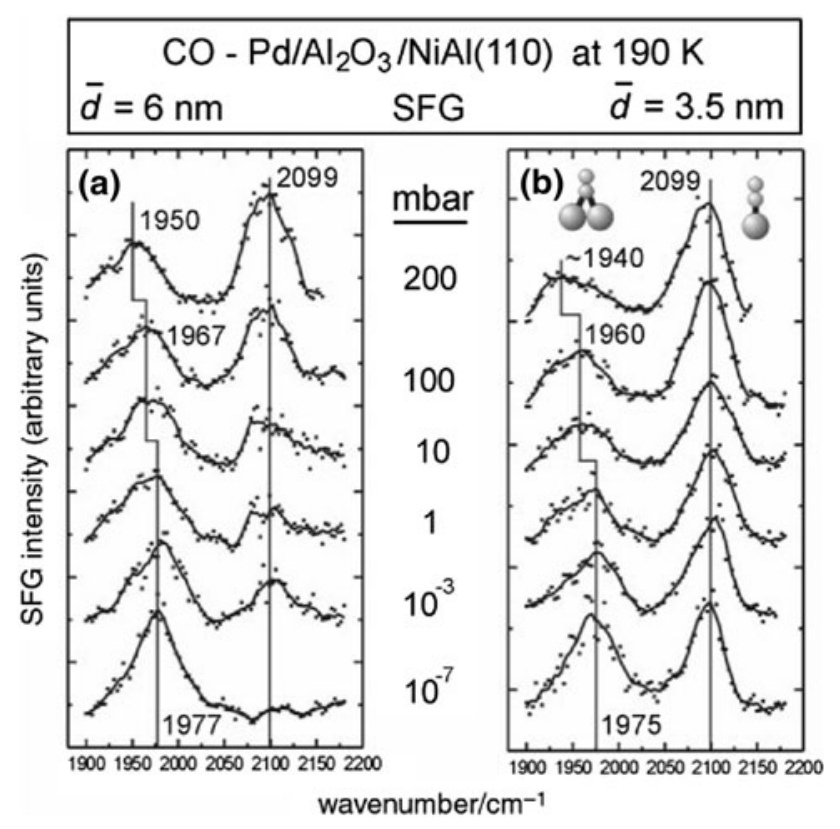

Fig. $5 \mathrm{CO}$ adsorption on alumina supported Pd nanoparticles via SFG [48]. a Relatively ordered Pd nanoparticles with an average diameter of $6 \mathrm{~nm}$ grown at $300 \mathrm{~K}$ and $\mathbf{b}$ defective $3.5 \mathrm{~nm}$ Pd particles grown at $90 \mathrm{~K}$. Population of a top sites is higher for defective/rough Pd particles particularly at low CO surface coverages

the presence of two bridging $\mathrm{CO}$ features at 1,853 and $1,882 \mathrm{~cm}^{-1}$ as well as two different atop $\mathrm{CO}$ features at 2,098 and $2,109 \mathrm{~cm}^{-1}$. It was demonstrated in this work that the presence of two different atop $\mathrm{CO}$ features are due to the coexistence of two different compressed $\mathrm{CO}$ overlayer domains [53]. $2,100 \mathrm{~cm}^{-1}$ signal was attributed to a $\mathrm{c}(7 \times \sqrt{ } 3)$ rect or a $\mathrm{c}(5 \times \sqrt{ } 3)$ rect domain which exists under kinetically hindered conditions below $200 \mathrm{~K}$. On the other hand, $2,110 \mathrm{~cm}^{-1}$ signal was associated to a Moiré structure (Fig. 6c) which is formed within 200-300 K. The same study also showed that similar vibrational signatures can also be also reproduced via SFG technique (Fig. 7b, c) where two atop features could be observed at $250 \mathrm{~K}$ while a single atop feature was detected at $300 \mathrm{~K}$. These results, combined with previous results in the literature, [29] suggested that although there is no obvious pressure gap for the $\mathrm{CO} / \mathrm{Pt}(111)$ adsorption system, existence of different ordered and compressed $\mathrm{CO}$ overlayers at high coverages strictly depends on the preparation conditions of the $\mathrm{CO}$ overlayer and the subsequent dosing parameters such as temperature and pressure.

3.1.1.4 CO/Cu/Pt(111) In a recent study, Andersson and Chorkendorff [56] investigated elevated-pressure CO adsorption on a CuPt surface alloy (SA) prepared on a Pt(111) substrate via PM-IRAS (Fig. 8). This study demonstrated that $\mathrm{CO}$ adsorption can be used to monitor the state of the $\mathrm{CuPt}(\mathrm{SA})$ under oxidizing or reducing conditions at elevated pressures. Figure 8 shows that $\mathrm{CO}$ adsorbs in only atop configuration on the $\mathrm{CuPt}(\mathrm{SA})$ in $\mathrm{UHV}$, while exposure to $200 \mathrm{mbar} \mathrm{O}_{2}$ decreases the surface coverage of $\mathrm{CO}$ due to $\mathrm{CO}$ oxidation/ $/ \mathrm{CO}_{2}$ formation as well as oxidation of the CuPt (SA). It was shown that this oxidized $\mathrm{CuPt}$ (SA) could be reduced to its original state by 100 mbar CO adsorption and subsequent evacuation to UHV. This study also demonstrated that elevated pressure $\mathrm{CO}$ reduction is a successful method to regenerate $\mathrm{CuPt}$ (SA) surfaces which are initially treated with $\mathrm{CO}+\mathrm{H}_{2}\left(\mathrm{P}_{\text {tot }}=220\right.$ mbar, $4 \%$ $\mathrm{CO})$ within $300-573 \mathrm{~K}$ or $\mathrm{CO}+\mathrm{H}_{2} \mathrm{O}\left(\mathrm{P}_{\text {tot }}=17\right.$ mbar, $50 \% \mathrm{CO}$ ) demonstrating the stability of this surface as a potentially versatile model catalyst system. 
Fig. 6 Ordered CO overlayers on $\mathrm{Pt}(111)$ at high coverages [53]: $\mathbf{a} \mathrm{c}(4 \times 2)$ or

$(2 \times \sqrt{3})$ rect at $\theta_{\mathrm{CO}}=0.5$,

b c $(7 \times \sqrt{3})$ rect $\left(\theta_{\mathrm{CO}}=0.71\right)$, c $(\sqrt{ } 19 \times \sqrt{ } 19) \mathrm{R} 23.4-13 \mathrm{CO}$ $\left(\theta_{\mathrm{CO}}=0.68\right)$

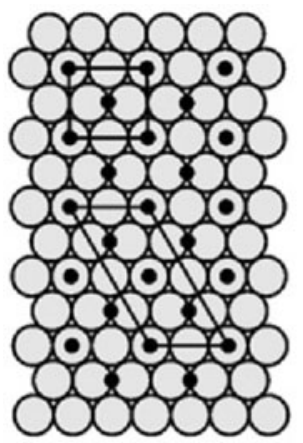

(a) $(2 \times \sqrt{3})$ rect

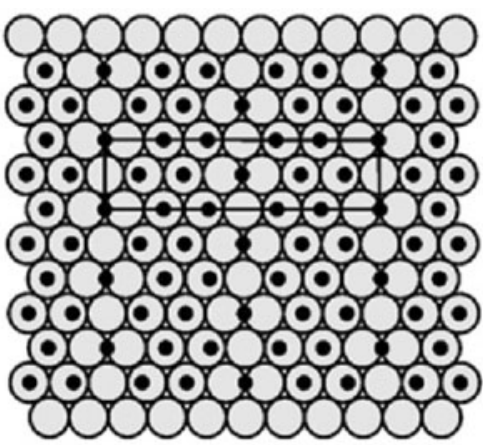

(b) $c(7 \times \sqrt{3})$ rect

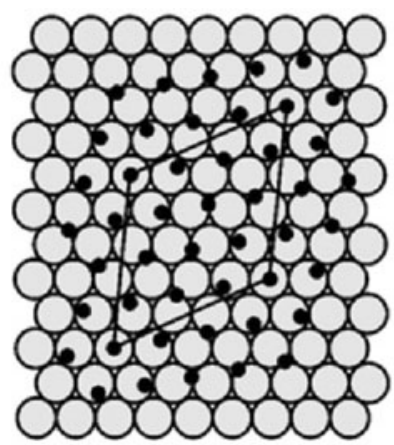

(c) $(\sqrt{19} \times \sqrt{19}) \mathrm{R} 23.4$ Moiré
Fig. $7 \mathrm{CO}$ adsorption on $\mathrm{Pt}(111)$ via a PM-IRAS within $10^{-9}$ mbar $<\mathrm{P}_{\mathrm{CO}}<100$ mbar at $300 \mathrm{~K}$ and via SFG within $10^{-5}$ mbar $<\mathrm{P}_{\mathrm{CO}}<100$ mbar at b $300 \mathrm{~K}$ and c $250 \mathrm{~K}$ [53]

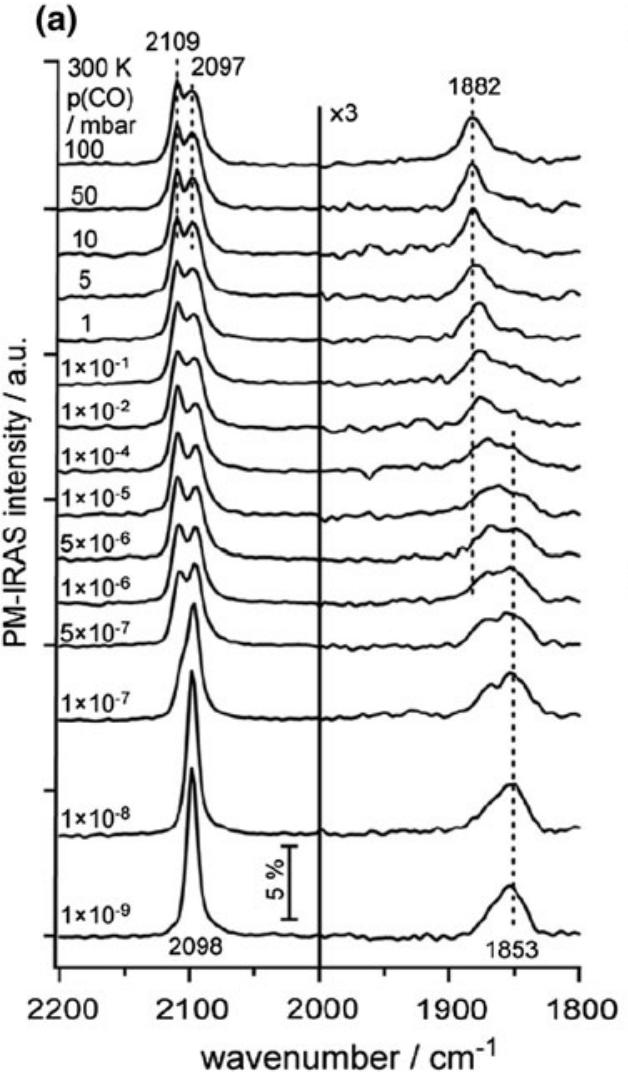

(b)
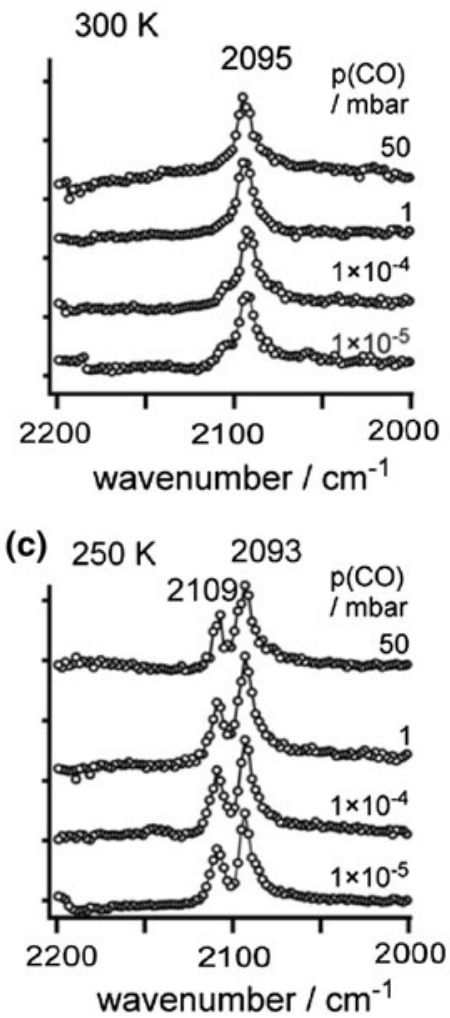

\subsubsection{5 СО/Аu(111), СO/Au(100) and CO/Au/TiO $/$} Pt(111) Although gold has been historically considered as a poorly active element in catalytic reactions, in their ground breaking study in 1989, Haruta et al. [57, 58] showed that $\mathrm{Au}$ can indeed be an extremely active metal in various catalytic reactions, especially when prepared in the form of supported nanoparticles. Later, Goodman and coworkers [59] demonstrated the quantum size effect for $\mathrm{Au}$ nanoparticles supported on $\mathrm{TiO}_{2}$, unraveling the complex alterations occurring in the electronic structure of $\mathrm{Au}$ nanoparticles as a function of particle size which had a direct impact on the catalytic activities of these systems. Owing to these pioneering studies as well as other similar studies, today there exists a large family of homogeneous and heterogeneous catalytic reactions which utilize $\mathrm{Au}$ as an active catalytic component [60]. Along these lines, investigation of $\mathrm{Au}$ model catalyst surfaces at elevated pressures via in situ vibrational spectroscopies [61-71] is of particular interest, since such studies provide invaluable fundamental information regarding the surface structure and the nature of the adsorption sites of the challengingly complex industrial Au-based catalysts.

Nakamura et al. [62] and Piccolo and co-workers [71] investigated $\mathrm{CO}$ adsorption on $\mathrm{Au}$ single crystal model catalyst surfaces at elevated pressures via PM-IRAS technique (Fig. 9). They observed that at $\mathrm{T}>273 \mathrm{~K}, \mathrm{CO}$ 
Fig. $8 \mathrm{CO}$ adsorption on $\mathrm{CuPt}$ surface alloy (SA) on Pt(111) at room temperature via PM-IRAS [56]. Spectrum (1) corresponds to $\mathrm{CO}$ adsorption on $\mathrm{CuPt}(\mathrm{SA})$ in UHV. Spectra (2-3) show the $\mathrm{CO}$ adsorbed on $\mathrm{CuPt}(\mathrm{SA})$ in UHV which is subsequently oxidized in 200 mbar $\mathrm{O}_{2}$. Spectrum (4) corresponds to the subsequent reduction of surface (3) in 100 mbar CO. Spectrum (5) corresponds to the evacuation of surface (4) to UHV conditions

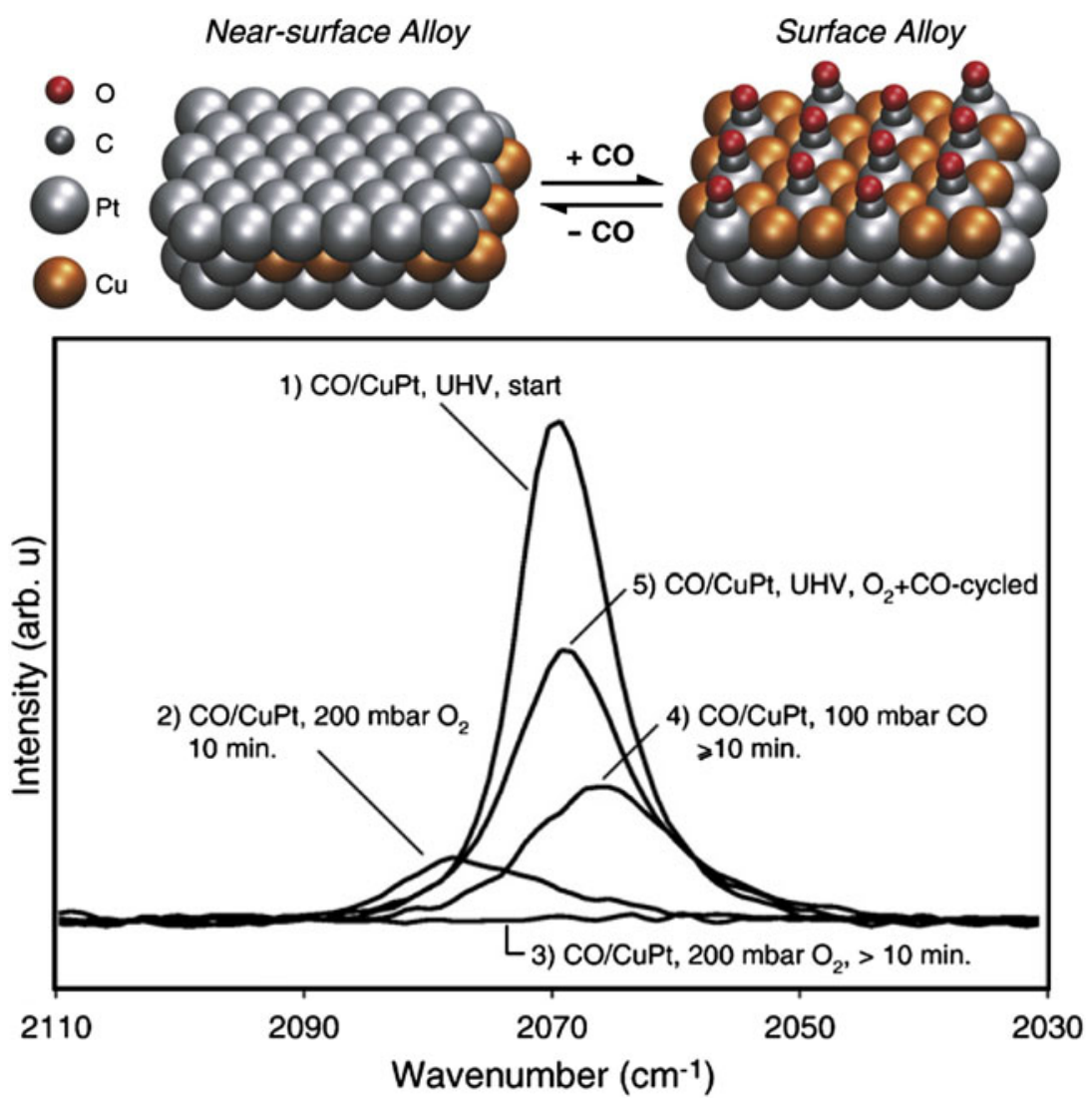

vibrational signal was below the detection limit for $\mathrm{CO}$ pressures less than $10^{-2}$ Torr. For CO pressures above $10^{-2}$ Torr, $\mathrm{CO}$ was found to adsorb in atop configuration on $\mathrm{Au}(100), \mathrm{Au}(111), \mathrm{Au}(311)$ [62] and $\mathrm{Au}(110)$ [71]. Nakamura et al. [62] also reported that while atop CO species adsorbed on the terraces of $\mathrm{Au}(100), \mathrm{Au}(111)$, $\mathrm{Au}(311)$ surfaces yielded a typical vibrational signature within 2,070-2,080 $\mathrm{cm}^{-1}, \mathrm{CO}$ adsorbed on step edges in an atop fashion revealed a higher vibrational frequency at $2,117 \mathrm{~cm}^{-1}$. This argument is in line with the work of Piccolo and co-workers [71] who observed an adsorbate (i.e. CO) induced reconstruction of the $\mathrm{Au}(110)$ surface via STM along with a CO vibrational signal at $2,110 \mathrm{~cm}^{-1}$ in PM-IRAS (Fig. 9d). Same authors also reported COinduced roughening of the $\mathrm{Au}(111)$ surface at elevated pressures [61].

In-situ vibrational spectroscopic studies at elevated pressures were also extended to 3D Au nanoparticles with various diameters deposited on $\mathrm{a} \mathrm{TiO}_{2}$ ultrathin film grown on a $\mathrm{Ru}(0001)$ substrate by Diemant et al. [66] (Fig. 10). These results showed that on these defective and relatively small 3D Au clusters, CO vibrational frequency appeared around $2,110 \mathrm{~cm}^{-1}$, consistent with the previous studies on $\mathrm{Au}$ single crystals suggesting that $\mathrm{CO}$ adsorbs in an atop fashion on Au clusters. Furthermore, $\mathrm{CO}$ adsorption energy values obtained from the PM-IRAS data suggested that the adsorption energy of $\mathrm{CO}$ decreases from 74 to $62 \mathrm{~kJ} / \mathrm{mol}$ as the average diameter of Au clusters increase from $2 \mathrm{~nm}$ to $4 \mathrm{~nm}$. In contrast, $\mathrm{CO}$ adsorption energies derived from $\mathrm{CO}+\mathrm{O}_{2}$ mixtures in a similar fashion revealed a value of $63 \mathrm{~kJ} / \mathrm{mol}$ which was independent of the Au particles size. Invariance in the $\mathrm{CO}$ adsorption energy as a function of $\mathrm{Au}$ particles size in the presence of $\mathrm{CO}+\mathrm{O}_{2}$ mixture was attributed to the interactions between adsorbed $\mathrm{CO}$ and oxygen as well as site blocking rather than any alterations in the electronic structure or morphology changes of $\mathrm{Au}$ particles [66]. Similar elevated-pressure CO adsorption experiments performed on $\mathrm{Au} / \mathrm{TiO}_{x} / \mathrm{Pt}(111)$ model catalyst surface containing reduced $\mathrm{TiO}_{x}$ nano-patches suggested that the $\mathrm{CO}$ chemisorption strength primarily depended on the Au nanoparticle size and morphology, where smaller $\mathrm{Au}$ particles revealed a higher affinity towards $\mathrm{CO}$, while the $\mathrm{Ti}$ oxidation state and the extent of reduction in the $\mathrm{TiO}_{x}$ layer did not play a significant role [63].

\subsubsection{NO Adsorption}

3.1.2.1 NO/Pd(111) NO adsorption on $\mathrm{Pd}(111)$ has been thoroughly studied via various vibrational spectroscopic techniques under UHV conditions [21]. These studies suggested that NO forms various coverage-dependent ordered overlayers on $\mathrm{Pd}(111)$ with typical NO vibrational 
Fig. 9 CO adsorption on various Au single crystal surfaces at elevated pressures via PM-IRAS. a-c $\mathrm{Au}(111)$, $\mathrm{Au}(100)$ and $\mathrm{Au}(311)$ at $273 \mathrm{~K}$, respectively [62] and $\mathbf{d ~} \mathrm{Au}(110)$ at $300 \mathrm{~K}$ [71] (a)

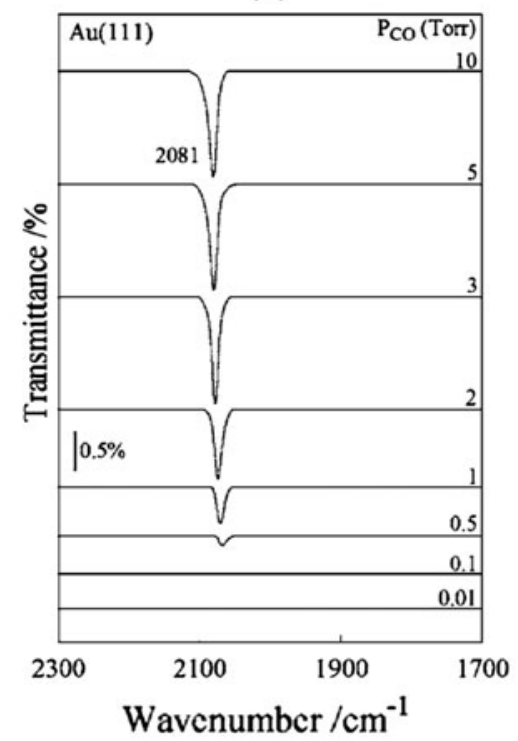

(c)

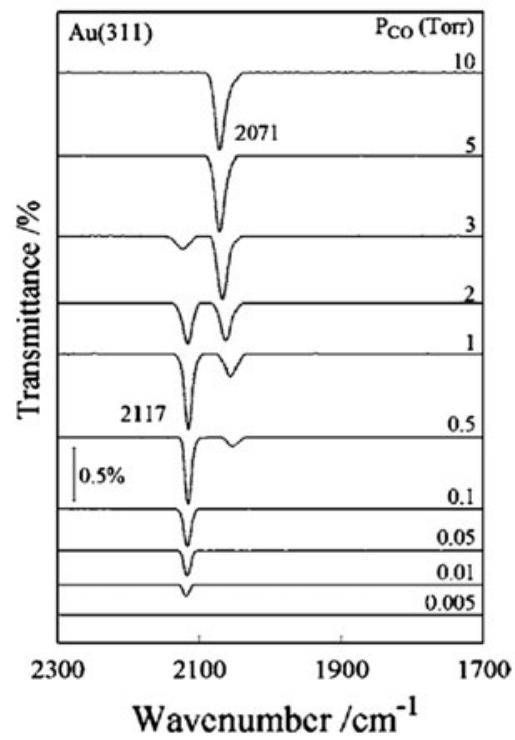

(b)

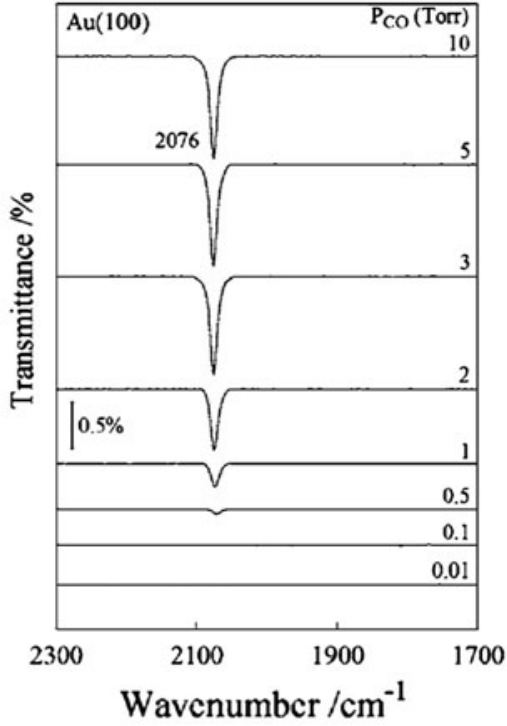

(d)

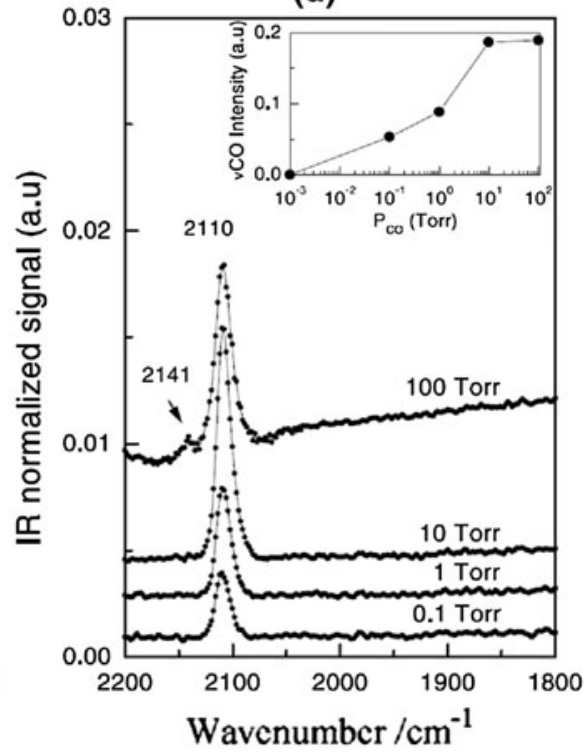

frequencies associated with various adsorption sites that are summarized in Fig. 11. NO adsorption experiments performed on $\mathrm{Pd}(111)$ at moderately high NO pressures such as 13.3 mbar (Fig. 12b) [22, 23] revealed that coverage-dependent NO overlayers formed under moderately high pressures are in good agreement with similar studies performed under UHV (Fig. 12a) [23, 72].

Although NO adsorption on $\operatorname{Pd}(111)$ within $10^{-6}$ 13.3 mbar seems to suggest that no high-pressure species are formed in this adsorption system, recent PM-IRAS results and complementary theoretical calculations performed by Ozensoy et al. [22, 23] (Figs. 12c, 13) [22] showed that under extremely high NO pressures (e.g. 400 mbar) a new high-pressure (compressed) ordered monomeric NO overlayer (i.e. $(3 \times 3)-7 \mathrm{NO})$ is formed revealing a higher NO surface $\operatorname{coverage}\left(\theta_{\mathrm{NO}}=0.778 \mathrm{ML}\right)$ than the conventional UHV saturation coverage of NO $\left(\mathrm{p}(2 \times 2)-3 \mathrm{NO}, \theta_{\mathrm{NO}}=0.75 \mathrm{ML}\right)$. The most prominent characteristic feature of this new high-pressure NO overlayer was the increased population of threefold hollow sites of the $\operatorname{Pd}(111)$ surface. It is worth mentioning that $((3 \times 3)-7 \mathrm{NO}$ structure is only observed under elevated temperature-pressure conditions $\left(300 \mathrm{~K}, P_{\mathrm{NO}}=400 \mathrm{mbar}\right)$ and it cannot be obtained by increasing the NO surface coverage in UHV even at extremely low temperatures (e.g. $25 \mathrm{~K})$ [23]. The lack of such a high coverage monomeric NO adsorption state at $25 \mathrm{~K}$ under UHV conditions suggests that formation of such a state requires a high 


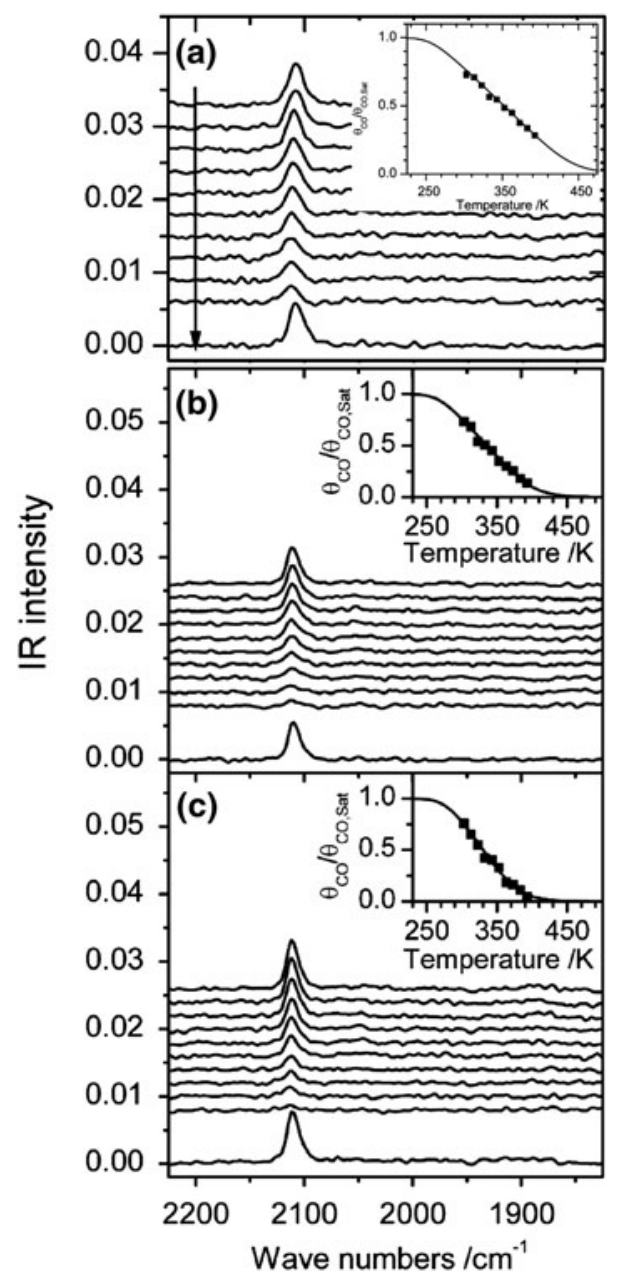

Fig. 10 PM-IRAS data for 10 mbar $\mathrm{CO}$ adsorption within $303-393 \mathrm{~K}$ on $\mathrm{Au}$ nanoparticles of varying sizes deposited on $\mathrm{TiO}_{2} /$ $\mathrm{Ru}(0001)$ [66]. In each panel, the topmost spectrum was obtained at $303 \mathrm{~K}$ and the temperature is increased with $10 \mathrm{~K}$ increments for each of the lower spectrum where the last (bottommost) spectrum was also obtained at $303 \mathrm{~K}$. Insets show the variation of the normalized CO surface coverage as a function of temperature. a $0.21 \mathrm{ML}$ Au deposit (two atomic layers thick, $\sim 2 \mathrm{~nm}$ diameter particles), b 0.9 ML Au deposit (4-5 atomic layers thick, $\sim 3 \mathrm{~nm}$ diameter particles), c 1.6 ML $\mathrm{Au}$ deposit (6 atomic layers thick, $\sim 4 \mathrm{~nm}$ diameter particles)

activation barrier which can be overcome only under elevated temperature and pressure conditions. These results particularly demonstrate that simple extrapolations based on UHV experiments at low temperatures and pressures may be misleading (at least for certain cases) for describing the elevated-pressure/temperature systems as these descriptions are only accurate as long as the thermodynamic equilibrium states are also kinetically accessible.

It has been reported in the literature that in addition to the monomeric adsorption states, $\mathrm{NO}$ can also form dimers on Pd(111) under UHV conditions at low temperatures, where NO surface coverage exceeds the monomeric saturation coverage and forms condensed multilayers [21]. However dimeric states of NO had never been reported to exist on $\operatorname{Pd}(111)$ at elevated temperatures and pressures until very recently, although such species are commonly observed on realistic high surface area catalysts under such conditions. Hess et al. [23] showed that by investigating $\mathrm{NO}$ adsorption via in situ PM-IRAS at high pressures (e.g. 400 mbar), existence of NO dimers (Pd-(ONNO)) and dinitrosyls (ON-Pd-NO) on Pd(111) single crystal model catalysts can be demonstrated (Fig. 14). Figure 14a illustrates the influence of the initial adsorption temperature on the nature of the high-coverage NO adsorption states formed on $\operatorname{Pd}(111)$ at 400 mbar NO pressure. Topmost spectrum in Fig. 14a corresponds to an initial adsorption temperature of $300 \mathrm{~K}$ where NO dissociation is hindered by the relatively low surface temperature. Under these conditions, a set of vibrational features located at 1855 , 1826, 1779 and $1537 \mathrm{~cm}^{-1}$ were observed, where 1779 , 1855 and $1537 \mathrm{~cm}^{-1}$ can be attributed to the NO dimer species and the $1,826 \mathrm{~cm}^{-1}$ can be assigned to the symmetric $\mathrm{N}=\mathrm{O}$ stretch of dinitrosyl species, i.e., a species where two NO molecules are bound to the same metal center.

On the other hand, when the initial NO adsorption is performed at $650 \mathrm{~K}$ (middle spectrum in Fig. 14a), due to NO dissociation and partial blocking of the $\mathrm{Pd}(111)$ adsorption sites by dissociation products (i.e. atomic $\mathrm{N}$ and O) only a monomeric $(3 \times 3)-7 \mathrm{NO}$ overlayer $\left(\theta_{\mathrm{NO}}=0.778 \mathrm{ML}\right)$ structure was obtained on $\mathrm{Pd}(111)$. Further NO dissociation induced by annealing this surface in the presence of $400 \mathrm{mbar} \mathrm{NO}$ pressure at $600 \mathrm{~K}$ and cooling back to $300 \mathrm{~K}$ (bottommost spectrum in Fig. 14a) results in the formation of the conventional monomeric UHV saturation coverage structure (i.e. $\mathrm{p}(2 \times 2)-3 \mathrm{NO}$, $\theta_{\mathrm{NO}}=0.75 \mathrm{ML}$ ). It is worth mentioning that indirect evidence for the NO dissociation on $\mathrm{Rh}(111)$ at 1 Torr and $300 \mathrm{~K}$ was also reported by Wallace et al. [73] where they have only observed atop NO adsorption on $\mathrm{Rh}(111)$ without threefold NO adsorption (possibly due to the occupation of the threefold sites by the NO dissociation products), although former UHV studies on this surface indicated the existence of threefold NO at high surface coverages. It is also important to point out that although dimer species can be obtained on $\mathrm{Pd}(111)$ under UHV conditions at $25 \mathrm{~K}$ by increasing NO exposure (Fig. 14 b), dinitrosyl species or the $(3 \times 3)-7 \mathrm{NO}$ monomeric compressed overlayer structure was not accessible in UHV.

\subsection{Co-adsorption and Reaction on Model Catalyst Surfaces at Elevated Pressures}

\subsubsection{CO + NO Co-adsorption and Reaction on Pd(111)}

It was illustrated in the previous sections that $\operatorname{Pd}(111)$ yields itself as an interesting model catalyst system where 
Fig. 11 Coverage-dependent ordered monomeric NO overlayers on $\mathrm{Pd}(111)$ under UHV conditions

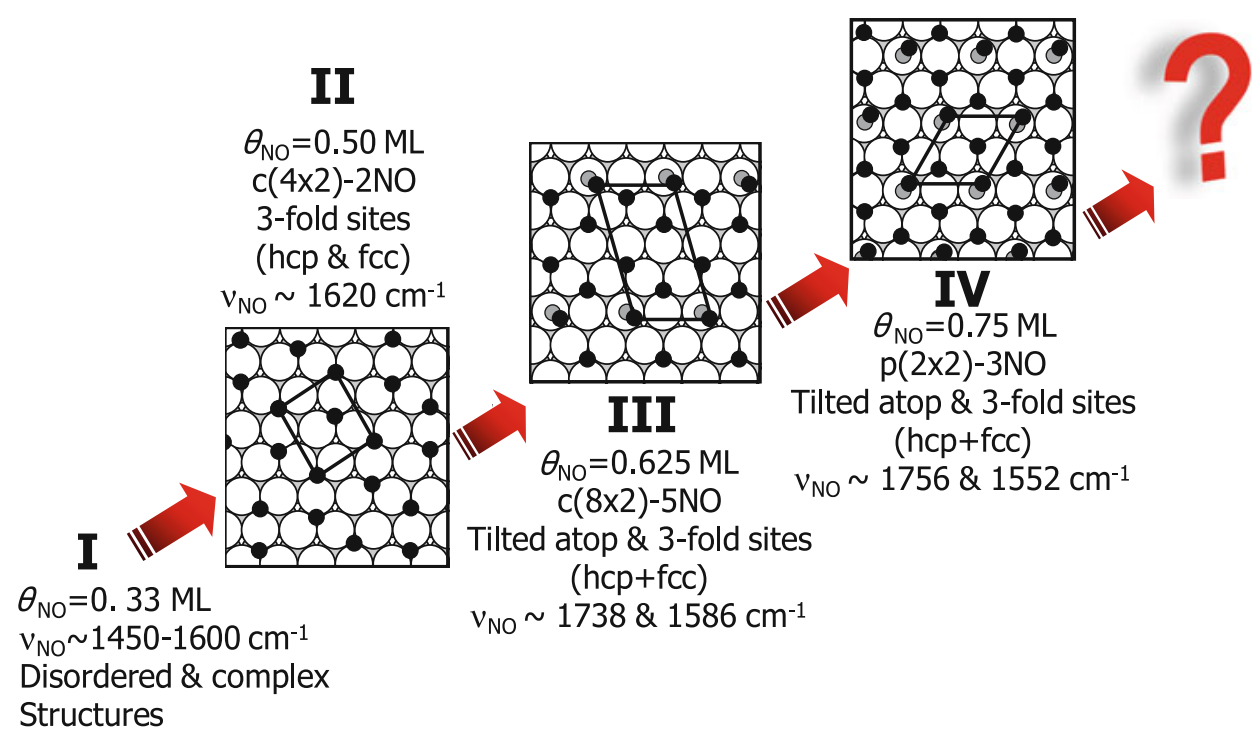

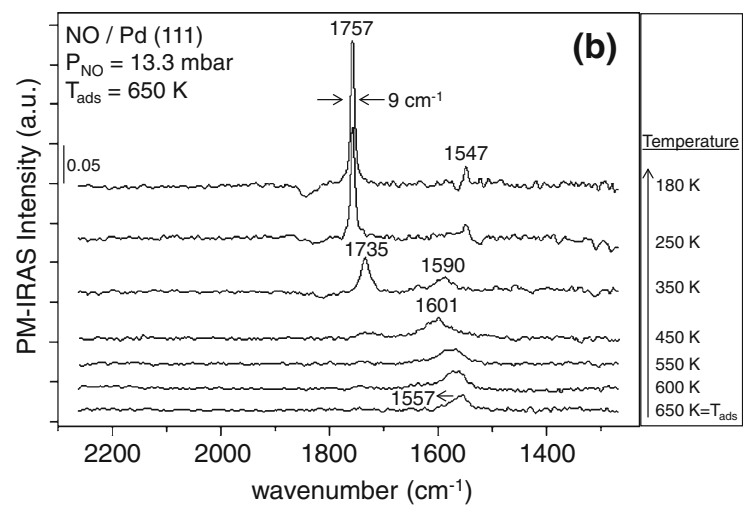

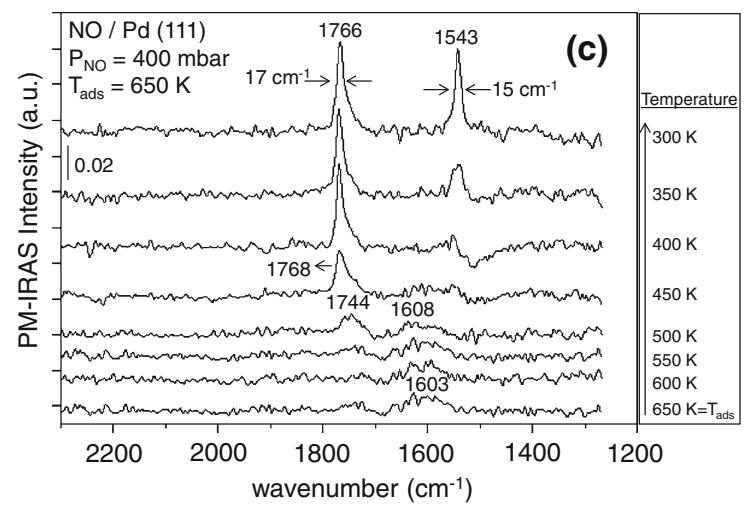

Fig. 12 NO adsorption on Pd(111) under a UHV (10 ${ }^{-6}$ mbar), b moderately high NO pressure (13.3 mbar) and c elevated NO pressure (400 mbar) [22, 23]

this surface reveals almost identical behavior in UHV and at elevated pressures when used with a particular probe molecule such as CO. In contrast, another simple diatomic probe molecule such as NO, leads to interesting and novel high-pressure states such as dinitrosyls or a compressed $(3 \times 3)-7 \mathrm{NO}$ monomeric overlayer structure which are only accessible upon kinetic activation at elevated temperatures and pressures. In a similar fashion, $\mathrm{CO}+\mathrm{NO}$ reaction on $\mathrm{Pd}(111)$ model catalyst surface has also proven to be interesting in terms of yielding new high-pressure species that cannot be observed under conventional UHV conditions. Former UHV surface science studies on the $\operatorname{Pd}(111), \operatorname{Pd}(100)$ and more advanced model catalysts prepared by depositing Pd nanoclusters on metal oxide 
Calculated mean chemisorption energies, surface free energies per unit area, bond distances and bond angles for $\mathrm{p}(2 \times 2)-3 \mathrm{NO}$ vs. $(3 \times 3)-7 \mathrm{NO}$ overlayers on Pd (111)

\begin{tabular}{lcc}
\hline & $\mathrm{p}(2 \times 2)-3 \mathrm{NO}$ & $(3 \times 3)-7 \mathrm{NO}$ \\
\hline$\theta_{\mathrm{NO}}(\mathrm{ML})$ & 0.75 & 0.778 \\
$<\mathrm{E}_{\text {ads }}>(\mathrm{eV} / \mathrm{NO}$ molecule $)$ & -1.76 & -1.67 \\
$\gamma\left(\mathrm{meV} / \AA^{2}\right)$ & -189 & -196 \\
$\mathrm{~d}_{\mathrm{N}-\mathrm{O}}(\AA)-$ atop site & 1.17 & 1.17 \\
$\mathrm{~d}_{\mathrm{N}-\mathrm{O}}(\AA)-$ fcc site & 1.21 & 1.20 \\
$\mathrm{~d}_{\mathrm{N}-\mathrm{O}}(\AA)-$ hcp site & 1.20 & 1.20 \\
$\mathrm{~d}_{\mathrm{Pd}-\mathrm{N}}(\AA)-$ atop site & 1.94 & 1.94 \\
$\mathrm{~d}_{\mathrm{Pd}-\mathrm{N}}(\AA)-$ fcc site & 2.08 & $2.07-2.11$ \\
$\mathrm{~d}_{\mathrm{Pd}-\mathrm{N}}(\AA)-$ hcp site & $2.08-2.10$ & $2.07-2.16$ \\
$\alpha_{\text {Pd-N-O }}\left({ }^{\circ}\right)-$ atop site & 129 & 131 \\
\hline
\end{tabular}

Simulated IRAS

$(3 \times 3)-7 \mathrm{NO} / \mathrm{Pd}(111)$

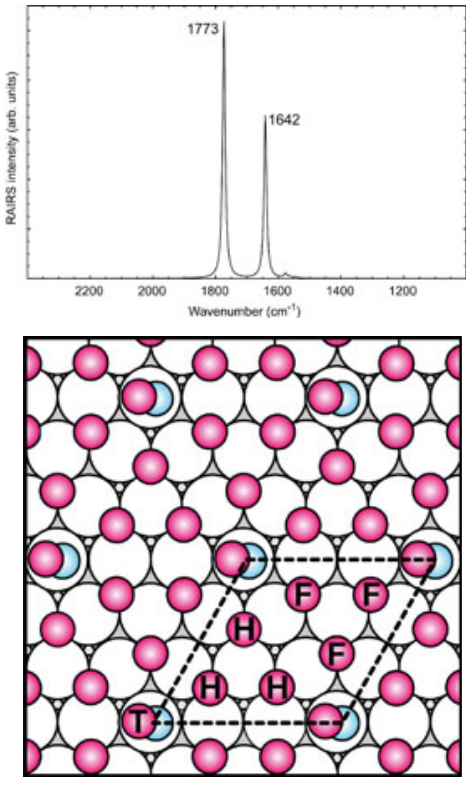

(3×3)-7NO/ Pd (111)

T: tilted atop site

$F$ : fcc hollow site

$\mathrm{H}$ : hop hollow site
Fig. 13 Comparison of the structural parameters of the conventional UHV saturation coverage NO overlayer on $\mathrm{Pd}(111)$ (i.e. $\mathrm{p}(2 \times 2)-$ $\left.3 \mathrm{NO}, \theta_{\mathrm{NO}}=0.75 \mathrm{ML}\right)$ and the high-pressure saturation coverage state (i.e. $\left.(3 \times 3)-7 \mathrm{NO}, \theta_{\mathrm{NO}}=0.778 \mathrm{ML}\right)$. Strong $1,642 \mathrm{~cm}^{-1}$ signal

ultrathin films grown on metallic substrates were reviewed in detail in recent reports and thus will not be elaborated here $[18,21]$.

The first in situ spectroscopic elevated pressure study for the $\mathrm{CO}+\mathrm{NO}$ reaction on $\mathrm{Pd}(111)$ planar model catalyst surface was performed by Ozensoy et al. [18, 24-26] where they exploited in situ PM-IRAS technique to investigate $\mathrm{CO}+\mathrm{NO}$ reaction at $240 \mathrm{mbar}$ (Fig. 15). In these studies, it was shown that in addition to the conventional monomeric $\mathrm{CO}$ and $\mathrm{NO}$ species that are adsorbed on various adsorption sites of the hexagonal $\operatorname{Pd}(111)$ surface (such as atop, bridging, threefold), presence of other surface reaction intermediates such as isocyanate $(-\mathrm{NCO})$ and isocyanic acid (HNCO) were also detected on $\operatorname{Pd}(111)$ at elevated temperatures and pressures where the source of $\mathrm{H}$ was suggested to be the bulk of the Pd crystal. Although -NCO and HNCO species have been detected [74] on numerous industrial supported precious metal catalysts during the $\mathrm{CO}+\mathrm{NO}$ reaction and in the presence of $\mathrm{H}_{2}$ or $\mathrm{H}_{2} \mathrm{O}$; such species have been elusive to detect in former UHV surface science studies. Thus, the in situ PM-IRAS experiments performed with $\mathrm{P}_{\mathrm{CO}+\mathrm{NO}}=10^{-6}, 10^{-4}, 10^{-2}$ and $10^{-1}$ mbar at $600 \mathrm{~K}$ (Fig. 15a) demonstrated that in the computationally simulated IRAS spectrum based on the $(3 \times 3)-7 \mathrm{NO}$ overlayer structure depicted in the figure is consistent with the increase in the population of the threefold sites in the experimental PM-IRAS results [22]

detection of $-\mathrm{NCO}$ and $\mathrm{HNCO}$ species requires a kinetic activation which can only be fulfilled at sufficiently high temperatures and pressures. It is worth emphasizing that there exists also additional controversial work in the literature regarding the existence of $\mathrm{HNCO}$ species on $\mathrm{Pd}$ single crystal surfaces $[75,76]$.

\subsection{2 $\mathrm{CO}+\mathrm{NO}$ Co-adsorption and Reaction on $\mathrm{AuPd}(100)$}

Elevated pressure $\mathrm{CO}+\mathrm{NO}$ reaction has also been recently investigated on more advanced bimetallic AuPd(100) model catalyst surfaces via in situ PM-IRAS technique (Fig. 16) [69]. These studies indicated that the alloy catalyst exhibited higher $\mathrm{CO}_{2}$ formation rates below $550 \mathrm{~K}$ than Pd single crystals due to the lower adsorption energy of $\mathrm{NO}$ and $\mathrm{CO}$ on the $\mathrm{AuPd}(100)$ surface leading to the presence of a larger number of available unoccupied surface sites for NO dissociation at lower temperatures. Furthermore, unlike Pd single crystal surfaces, adsorption energy of $\mathrm{NO}$ was found to be lower than that of $\mathrm{CO}$ for the $\mathrm{CO}: \mathrm{NO}=1: 1$ mixture. Also, $\mathrm{CO}+\mathrm{NO}$ reaction on the $\operatorname{AuPd}(100)$ alloy surface revealed significantly different 
(a)

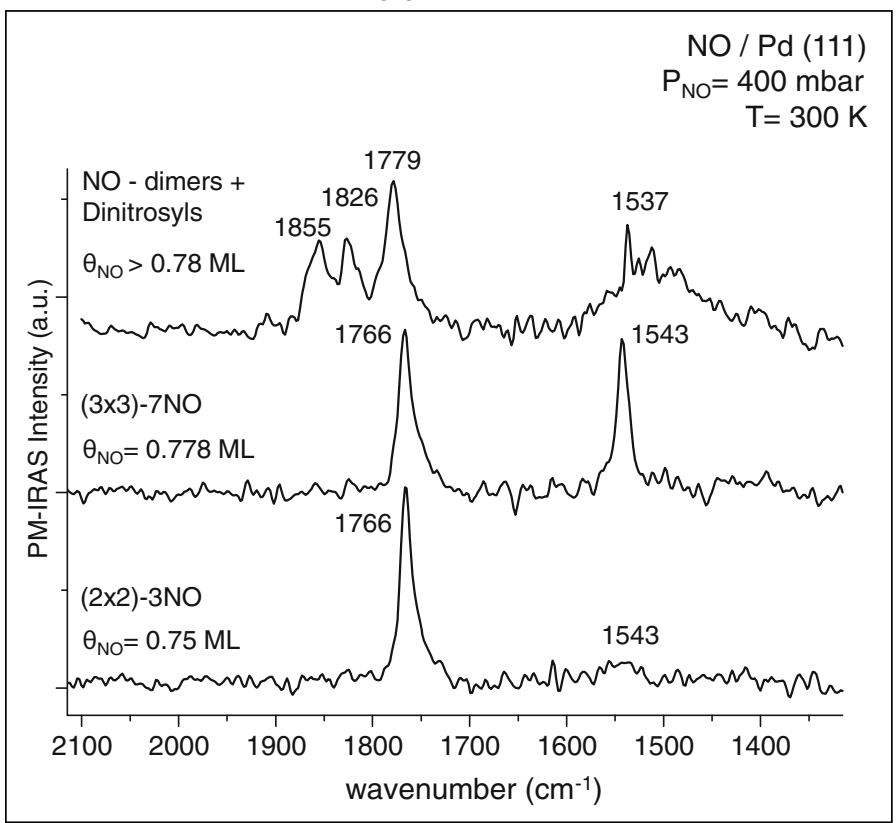

(b)

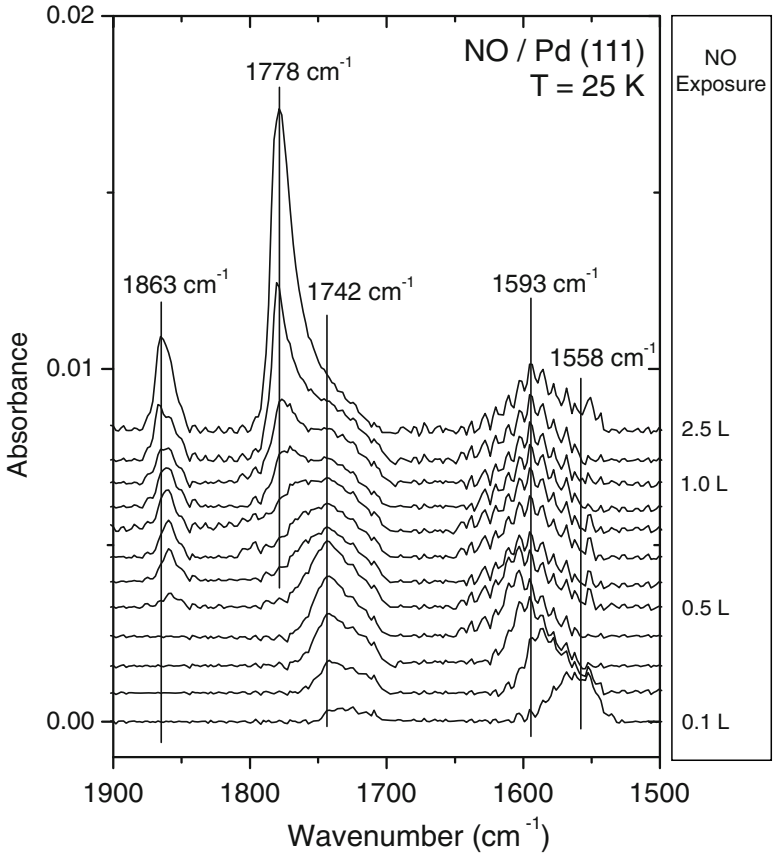

(c)

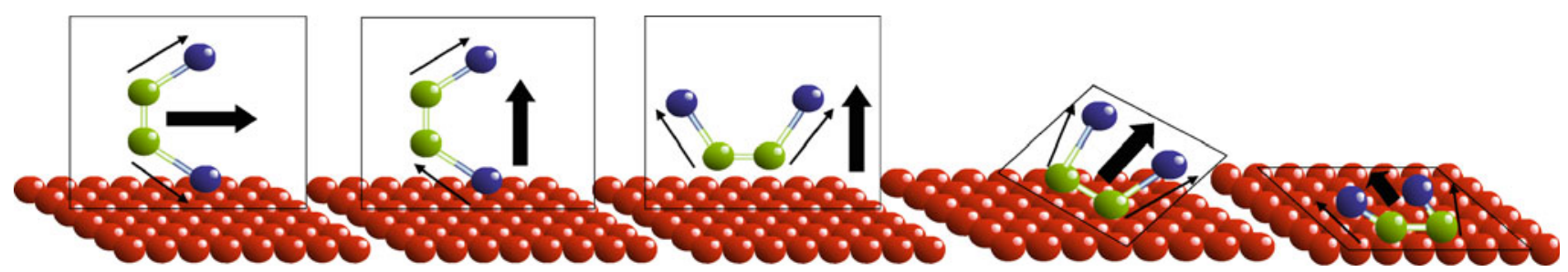

Fig. 14 a In situ PM-IRAS data for NO adsorption on Pd(111) at $\mathrm{P}_{\mathrm{NO}}=400$ mbar and $\mathrm{T}=300 \mathrm{~K}$ after various pretreatments: (top) initial adsorption at $300 \mathrm{~K}$; (middle) initial adsorption at $650 \mathrm{~K}$ and subsequent cooling to $300 \mathrm{~K}$; (bottom) initial adsorption at $650 \mathrm{~K}$, cooling back to $300 \mathrm{~K}$, second annealing at $600 \mathrm{~K}$, cooling back to
300 K. b Coverage-dependent NO adsorption on Pd(111) in UHV at $25 \mathrm{~K}$ indicating the formation dimers (but no dinitrosyls). c Some of the possible adsorption configurations of NO dimmers on $\mathrm{Pd}(111)$ [23]

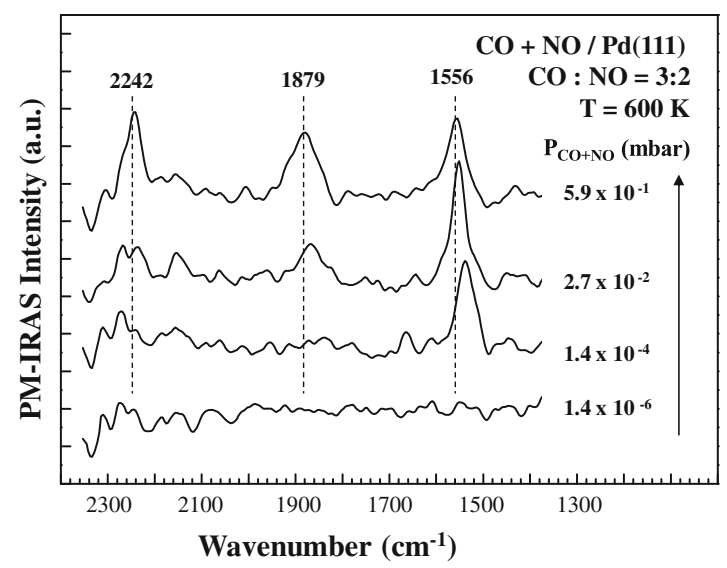

Fig. 15 a In-situ PM-IRAS data for $\mathrm{CO}+\mathrm{NO}$ reaction on $\mathrm{Pd}(111)$ at $600 \mathrm{~K}$ and at various pressures showing the pressure barrier for the detection of $-\mathrm{NCO} / \mathrm{HNCO}$ species [24]. b Observation of $-\mathrm{NCO}$ and

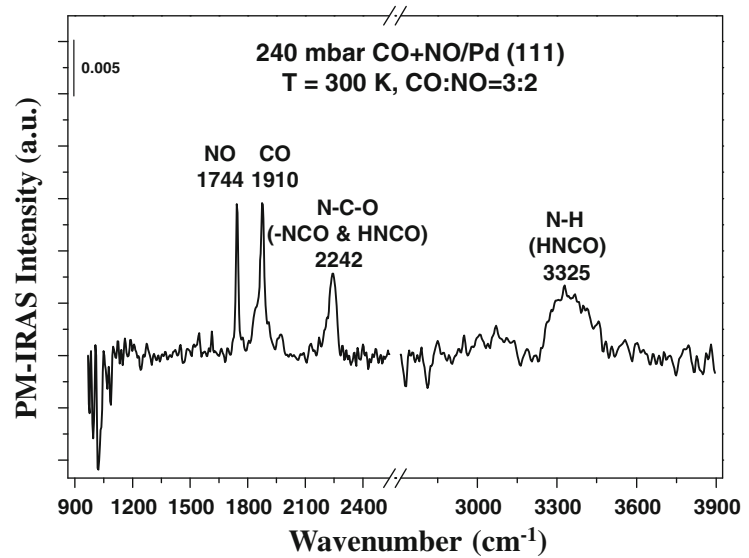

HNCO species during CO + NO reaction on $\mathrm{Pd}(111)$ at 240 mbar. Spectrum was obtained by dosing the gas mixture at $600 \mathrm{~K}$ and subsequently cooling to $300 \mathrm{~K}$ [26] 
$\mathrm{CO}$ and NO reaction orders and a much higher selectivity towards $\mathrm{N}_{2}$, suggesting that Au promotion in conventional three way catalysts (TWC) may assist solving the "cold start" problem.

Two global reaction pathways were proposed for this system [69]:

$$
\begin{aligned}
& \mathrm{CO}+\mathrm{NO} \rightarrow \mathrm{CO}_{2}+1 / 2 \mathrm{~N}_{2} \\
& \mathrm{CO}+2 \mathrm{NO} \rightarrow \mathrm{CO}_{2}+\mathrm{N}_{2} \mathrm{O}
\end{aligned}
$$

With the following elementary reaction steps:

$$
\begin{aligned}
& \mathrm{CO}(\mathrm{g}) \leftrightarrow \mathrm{CO}(\text { ads }) \\
& \mathrm{NO}(\mathrm{g}) \leftrightarrow \mathrm{NO}(\text { ads }) \\
& \mathrm{NO}(\text { ads }) \rightarrow \mathrm{N}(\text { ads })+\mathrm{O}(\text { ads }) \\
& \mathrm{NO}(\text { ads })+\mathrm{N}(\text { ads }) \rightarrow \mathrm{N}_{2}+\mathrm{O}(\text { ads })
\end{aligned}
$$

$2 \mathrm{~N}($ ads $) \rightarrow \mathrm{N}_{2}$

$\mathrm{NO}($ ads $)+\mathrm{N}($ ads $) \rightarrow \mathrm{N}_{2} \mathrm{O}$

$\mathrm{CO}($ ads $)+\mathrm{O}($ ads $) \rightarrow \mathrm{CO}_{2}$.

It was demonstrated in this study that the global reaction pathway (1) dominates the AuPd(100) catalyst. Relatively small NO vibrational signals in Fig. 16a and b, supports the decreased adsorption strength of $\mathrm{NO}$ with respect to $\mathrm{CO}$ on the $\operatorname{AuPd}(100)$ model catalyst surface at various temperatures, total pressure and relative gas compositions. Two different kinetic regimes were apparent for the $\mathrm{CO}+\mathrm{NO}$ reaction the $\operatorname{AuPd}(100)$ surface (Fig. 16c): a lower activation energy regime below $500 \mathrm{~K}$ corresponding to an apparent activation energy of $23 \mathrm{~kJ} / \mathrm{mol}$ and a higher activation energy regime above $500 \mathrm{~K}$ with an apparent activation energy of $40 \mathrm{~kJ} / \mathrm{mol}$. Figure $16 \mathrm{~d}$ also clearly

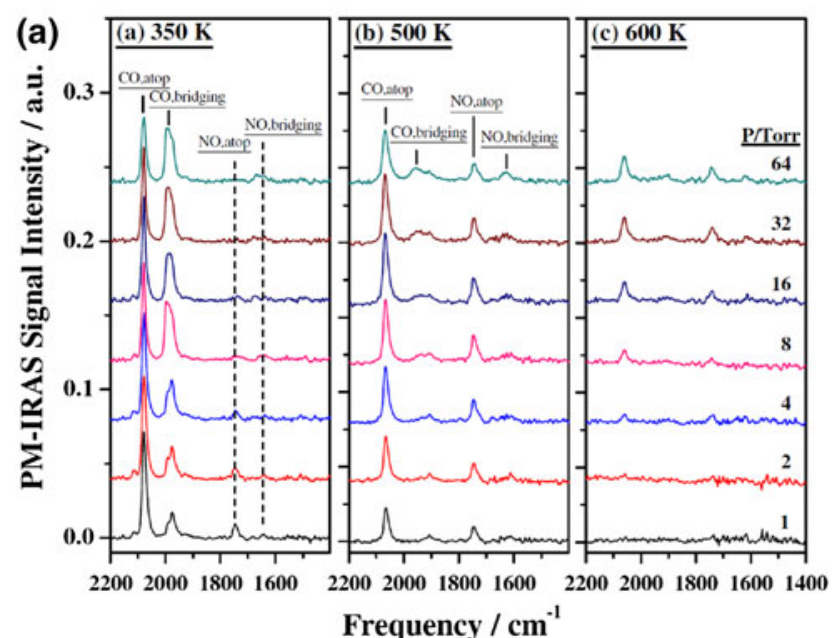

(c)

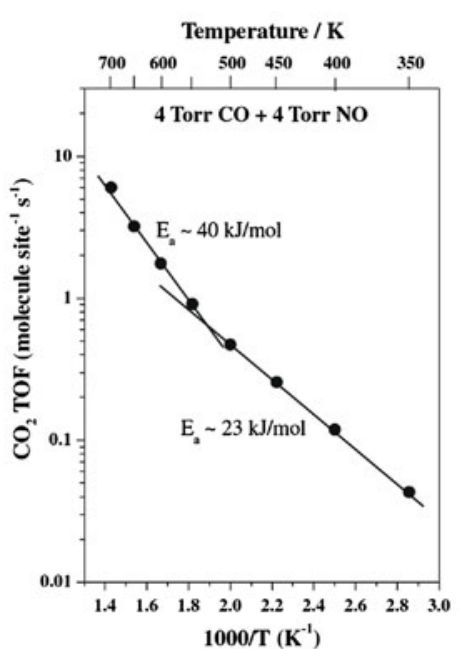

Fig. 16 a In-situ PM-IRAS data for $\mathrm{CO}+\mathrm{NO}$ reaction on $\mathrm{AuPd}(100)$ surface at 350,500 and $600 \mathrm{~K}$ under $\mathrm{P}_{\mathrm{CO}+\mathrm{NO}}=$ 1-64 Torr where CO:NO ratio is equal to 1 . b In-situ PM-IRAS data for $\mathrm{CO}+\mathrm{NO}$ reaction on $\mathrm{AuPd}(100)$ at 350 for various CO:NO (b)

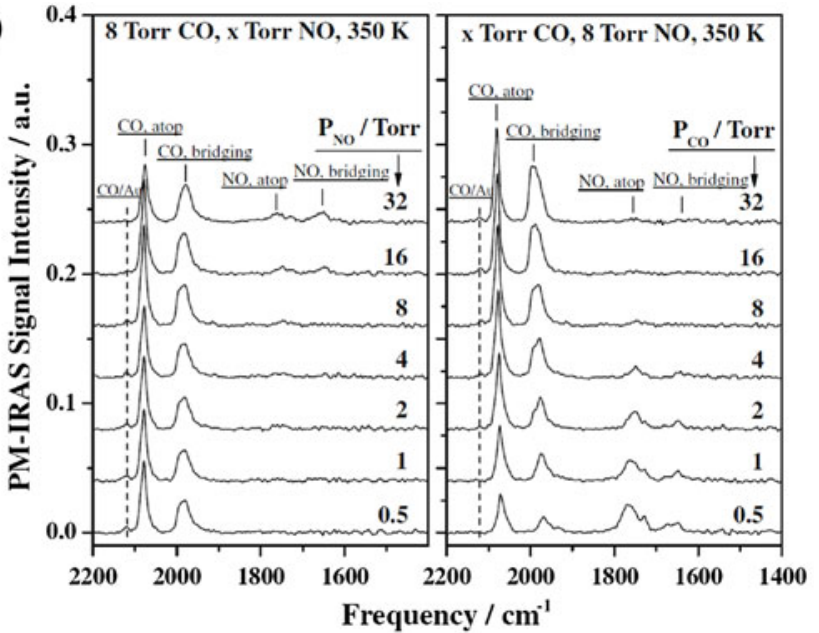

(d)

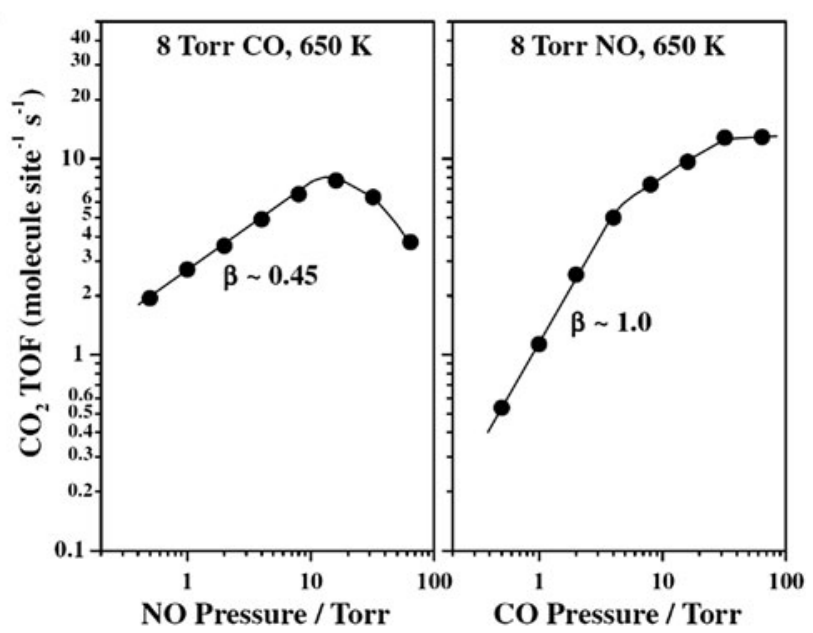

relative compositions. c Arrhenius plot for $\mathrm{CO}+\mathrm{NO}$ reaction on AuPd(100) (4 Torr CO +4 Torr NO). d $\mathrm{CO}_{2}$ conversion as function of varying $\mathrm{NO}$ and $\mathrm{CO}$ partial pressures at $650 \mathrm{~K}$ [69] 
indicates that at low $\mathrm{CO}$ and $\mathrm{NO}$ pressures, positive orders of reaction rates were detected for both $\mathrm{CO}$ and $\mathrm{NO}$, indicating that due to the low adsorption energy of $\mathrm{CO}$ and NO on the AuPd(100) surface, none of these reactants act as inhibitors or surface site blockers. On the other hand for NO-rich compositions reaction rate was found to be decreasing with increasing NO partial pressure, revealing the negative effect of site blocking upon the accumulation of atomic $\mathrm{N}$ and atomic $\mathrm{O}$ (i.e. NO dissociation products) on the surface.

The same study [69] also investigated the $\mathrm{CO}+\mathrm{O}_{2}+\mathrm{NO}$ reaction on the $\operatorname{AuPd}(100)$ bimetallic alloy surface at elevated pressures, where it was reported that low-pressure $\mathrm{NO}$ promotes $\mathrm{CO}+\mathrm{O}_{2}$ reaction via the formation of gas phase $\mathrm{NO}_{2}$, providing a more efficient atomic oxygen supplier than $\mathrm{O}_{2}$ below $600 \mathrm{~K}$. However above a critical NO pressure, $\mathrm{NO}_{2}$ leads to the surface oxidation, inhibiting $\mathrm{CO}_{2}$ formation. Furthermore, it was also demonstrated that $\mathrm{Pd} / \mathrm{Au}$ surface atom ratio on the $\operatorname{AuPd}(100)$ alloy undergoes variations as a function of the composition and the total pressure of the reactant mixture and these subtle, yet important changes can be effectively followed by the powerful PM-IRAS technique.

\subsection{3 $\mathrm{CO}+\mathrm{H}_{2}$ Co-adsorption and Reaction}

3.2.3.1 $\mathrm{CO}+\mathrm{H}_{2}$ Co-adsorption and Reaction on $\mathrm{Co}(0001) \mathrm{CO}+\mathrm{H}_{2}$ co-adsorption and reaction is particularly important for Fisher-Tropsch (FT) reaction where cobalt based supported catalysts are actively used in the industry. Thus, $\mathrm{CO}+\mathrm{H}_{2}$ system was studied at elevated pressures on $\mathrm{Co}(0001)$ model catalyst surfaces by Shell research laboratories [77]. It was shown that the clean/lowdefect density $\operatorname{Co}(0001)$ surface functions as a methanation catalyst with a low chain growth probability $(\alpha)$ factor, rather than a true FT catalyst [77-79]. On the other hand, polycrystalline Co foils exhibiting a high surface defect density was found to be more efficient FT catalysts with a higher $\alpha$ factor. Thus, Oosterbeek exploited PM-IRAS technique in order to investigate $\mathrm{CO}$ adsorption on clean $\mathrm{Co}(0001)$ surface and determined the $\mathrm{CO}$ adsorption configurations (Fig. 17a). At low pressures, $\mathrm{CO}$ preferred atop sites while increasing pressure led to threefold and bridging adsorption configurations. $\mathrm{CO}$ adsorption on an annealed (low-defect density) Co(0001) surface was also compared with that of a defective $\mathrm{Co}(0001)$ model catalyst surface which was prepared via extensive ion bombardment (Fig. 17b). It was shown that the presence of defects led to the appearance of an additional $\mathrm{CO}$ atop adsorption state having a characteristically higher vibrational frequency than that of the regular atop $\mathrm{CO}$ adsorbed on low-defect density terraces. These new defect states were both observed under UHV conditions with a $\mathrm{CO}$ exposure of
$10 \mathrm{~L}\left(1 \mathrm{~L}=10^{-6}\right.$ Torr $\left.\times \mathrm{s}\right)$ as well as at elevated pressures (i.e. $\mathrm{P}_{\mathrm{CO}}=100 \mathrm{mbar}$ ). Upon dosing of the syngas $\left(\mathrm{SG}=\mathrm{CO}+\mathrm{H}_{2}\right)$ at $493 \mathrm{~K}$, it was found that the atop $\mathrm{CO}$ adsorbed on the low-defect density terrace sites remained intact as spectator species, while the vibrational signal for the atop $\mathrm{CO}$ adsorbed on defect sites irreversibly attenuated, suggesting the active involvement of these sites in the polymerization and chain growth (FT) process. It was also shown that the hydrocarbon production was proportional to the surface defect density [77-79].

\subsubsection{2 $\mathrm{CO}+\mathrm{H}_{2}$ Co-adsorption and Reaction on Pd(111)} and $\mathrm{Pd} / \mathrm{Al}_{2} \mathrm{O}_{3} / \mathrm{NiAl}(110) \quad \mathrm{CO}+\mathrm{H}_{2}$ co-adsorption and reaction at elevated pressures were also studied on clean and defect rich Pd(111) as well as Pd clusters deposited on alumina ultrathin films via SFG technique $[42,80,81]$. These studies revealed that clean $\operatorname{Pd}(111)$ single crystals surface was relatively unreactive for $\mathrm{CO}$ hydrogenation, mostly due to $\mathrm{CO}$ poisoning of the catalyst surface, while formation of $\mathrm{CH}_{x} \mathrm{O}$ species (i.e. indication of $\mathrm{CO}$ hydrogenation) was observed on the defect-rich $\mathrm{Pd}(111)$ model catalyst surface [42]. In a similar fashion, generation of trace amounts of methane and methanol was also detected upon high-pressure $\mathrm{CO}+\mathrm{H}_{2}$ adsorption on the $\mathrm{Pd} / \mathrm{Al}_{2} \mathrm{O}_{3} /$ $\mathrm{NiAl}(110)$ model catalyst surface [81]. Indications for surface roughening on clean $\operatorname{Pd}(111)$ was also reported upon high pressure $\mathrm{CO}+\mathrm{H}_{2}$ adsorption [81].

\subsection{4 $\mathrm{CO}+\mathrm{O}_{2}$ Co-adsorption and $\mathrm{CO}$ Oxidation Reaction}

$\mathrm{CO}$ oxidation is a widely used test reaction for demonstrating the activity of heterogeneous catalytic prototypes. Thus, there exist a vast number of surface science studies elucidating the mechanism of this very important reaction over a large number of different model catalyst systems under various reaction conditions. Thus in this review, rather than providing a comprehensive "grand survey" of the mechanism of the $\mathrm{CO}+\mathrm{O}_{2}$ reaction on the previously investigated model catalyst surfaces under different reaction regimes, we will focus on various selected examples from the recent literature [64, 67-70, 82-97], demonstrating the power of the surface-sensitive in situ vibrational spectroscopic techniques at elevated pressures and highlight some of the very critical, yet controversial points which are subject of intense discussion in the current literature. For a detailed discussion on some of the general aspects of the heterogeneous catalytic $\mathrm{CO}$ oxidation reaction, the reader is referred to a recent review article and references therein [98].

Although seemingly a simple reaction, $\mathrm{CO}$ oxidation reaction on PGMs constitutes some of the most characteristic genres of mechanistic micro steps that are 
(a)

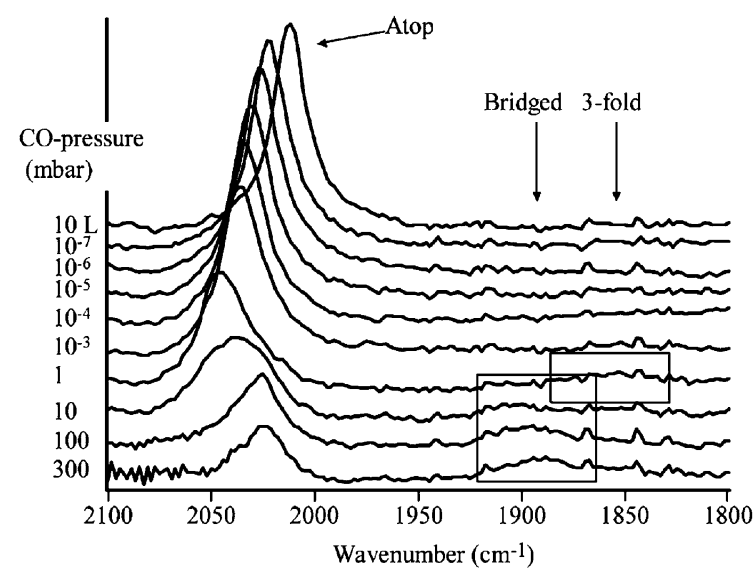

Fig. 17 a In-situ PM-IRAS data for $\mathrm{CO}$ adsorption on clean $\mathrm{Co}(0001)$ at room temperature (RT). b PM-IRAS data for $\mathrm{CO}$ and $\mathrm{CO}+\mathrm{H}_{2}$ (syngas) adsorption on low-defect density (annealed) and defective $\mathrm{Co}(0001)$ surfaces. CO adsorption is presented for UHV

ubiquitous for many heterogeneous catalytic reactions, such as molecular adsorption and desorption of a reactant $(\mathrm{CO}(\mathrm{g}) \leftrightarrow \mathrm{CO}(\mathrm{ads}))$, dissociative adsorption of a reactant $\left(\mathrm{O}_{2}(\mathrm{~g}) \leftrightarrow 2 \mathrm{O}(\mathrm{ads})\right)$, reactive combination of adsorbates $\left(\mathrm{CO}(\right.$ ads $)+\mathrm{O}($ ads $\left.) \rightarrow \mathrm{CO}_{2}(\mathrm{~g})\right)$, competition for adsorption sites leading to inhibition/poisoning, adsorbate induced surface morphology changes, surface/bulk oxide formation and oscillatory behavior (bistability) [64, 67-70, 82-98]. Goodman et al. provided some of the most recent and extensive studies on the $\mathrm{CO}+\mathrm{O}_{2}$ reaction on PGM single crystal model catalyst surfaces (e.g. Pt, Pd, Rh, Ru, AuPd) at elevated pressures via PM-IRAS technique $[64,67-70,82-90]$ which will form the main focus of this review.

It is generally accepted that Langmuir-Hinshelwood reaction mechanism is valid for the CO oxidation on PGM single crystal surfaces at both low-pressure (i.e. UHV) as well as high-pressure (i.e. close to atmospheric pressure) conditions where the molecularly adsorbed $\mathrm{CO}$ reacts with the atomic oxygen on the surface (generated via dissociative adsorption of $\mathrm{O}_{2}(\mathrm{~g})$ ) forming $\mathrm{CO}_{2}$ which quickly desorbs from the surface [64, 67-70, 82-98]. In other words, no "pressure-gap" effects were found on typical PGM single crystal model catalyst surfaces [88].

Under low pressure conditions, inhibition of $\mathrm{O}_{2}$ adsorption due to a high $\mathrm{CO}$ (ads) coverage was found to be a much stronger factor than the alternative inhibition process associated with the inhibition of $\mathrm{CO}(\mathrm{ads})$ by atomic (surface) oxygen [88]. Thus the optimum reaction conditions under low pressures involve a low $\mathrm{CO}$ surface coverage. At low temperatures and pressures (i.e. under low reaction rate regime), reaction rate is limited by the $\mathrm{CO}$ (b)

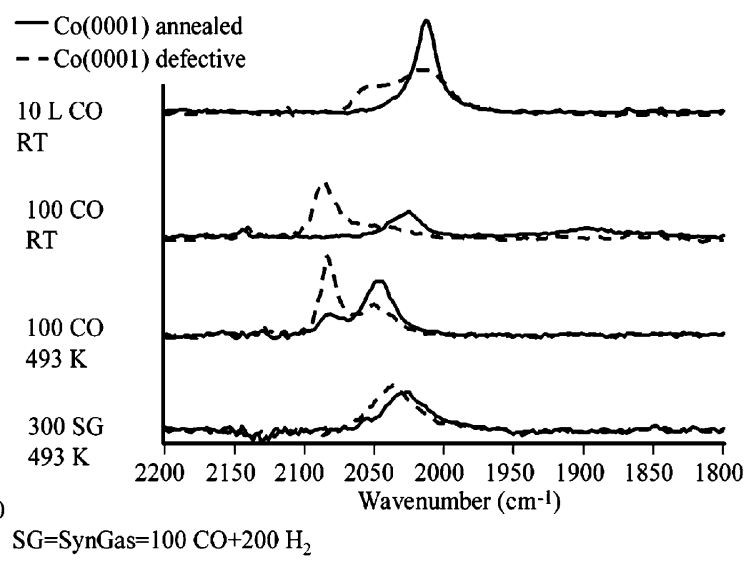

conditions $(10 \mathrm{~L})$ at RT, $100 \mathrm{mbar}$ at RT and $100 \mathrm{mbar}$ at $493 \mathrm{~K}$ while 300 mbar of syngas $\left(100\right.$ mbar $\left.\mathrm{CO}+200 \mathrm{mbar} \mathrm{H}_{2}\right)$ was dosed at $493 \mathrm{~K}$

poisoning. Thus, increasing temperature under these conditions has a positive effect on the reaction rate until particularly high temperatures are reached, where the reaction rate starts to be limited by the surface oxygen inhibition decreasing the $\mathrm{CO}$ surface residence time and $\mathrm{CO}$ surface coverage. Such O-rich surfaces correspond to a high reaction rate regime [88]. Hence, most of the kinetic aspects of the $\mathrm{CO}$ oxidation reaction on PGM can be elucidated by considering the inhibition (competitive adsorption) pathways and the oscillatory oxidation/reduction of the catalyst surface. Therefore, ultimate reactivity could be obtained by optimizing the reaction conditions in order to control CO-inhibition/O-inhibition and oxidation of the PGM catalyst.

Under high pressure conditions, $\mathrm{CO}$ oxidation reaction on PGM single crystal model catalyst surfaces tend to have three typical kinetic regimes: (i) CO-inhibited low temperature regime with a low reaction rate, where the rate is controlled by $\mathrm{CO}$ desorption from the surface, (ii) a mass transfer limited (MTL) regime with a high reaction rate and (iii) a transient hyperactive (extremely fast) regime in between the first two regimes which is not controlled by MTL [82]. Under high pressures and low temperatures (CO-inhibited conditions), reaction rate exhibits first order dependence on $\mathrm{O}_{2}$ partial pressures and a negative $(\sim-1)$ order dependence on $\mathrm{CO}$ partial pressures where the reaction rate is directly controlled by the rate of $\mathrm{CO}$ desorption from the surface. It has been reported that the apparent activation energies $\left(E_{a}\right)$ of the $\mathrm{CO}$ oxidation reaction on $\mathrm{Pt}, \mathrm{Pd}, \mathrm{Rh}$ model catalysts were about $110 \mathrm{~kJ} / \mathrm{mol}$ which is very close to the $\mathrm{CO}$ desorption energies of these surfaces. Thus under these conditions, reaction is clearly 
structure insensitive. Ru exhibits an anomaly among other PGM, where although Ru is the least active surface at low pressures, it is found to be the most active surface at high pressures [83]. Higher activity of the Ru surface at elevated pressures and low temperatures was attributed to the higher tendency of this surface to be covered with oxygen atoms, reaching a CO-uninhibited regime more readily [83]. On Pd and Rh surfaces, under high pressures and high $\mathrm{O}_{2}$ partial pressures, reaction was found to be inhibited by the deactivation due to oxidation of the metal catalysts forming oxide phases, however metallic Pt model catalysts were observed to be much more resistant towards surface oxidation, requiring extremely high oxygen partial pressures for deactivation (Fig. 18) [83]. Next few sections of this review, concentrate on the elevated-pressure $\mathrm{CO}$ oxidation reaction studies performed on a selected set of PGM single crystal model catalyst surfaces providing spectroscopic and kinetic evidences for the arguments discussed above.

\subsubsection{CO Oxidation on $R h(111)$ Figure 19 presents a} set of PM-IRAS results [82] obtained at different CO oxidation reaction conditions on $\mathrm{Rh}(111)$ whose overall kinetic behavior is described in Fig. 18a [88]. It is apparent that below $450 \mathrm{~K}$ (i.e. under low reaction rate conditions) $\mathrm{CO}$ is typically found to adsorb in both atop (with $v_{\mathrm{CO}}<2,100 \mathrm{~cm}^{-1}$ ) and threefold configurations (with $1,850 \mathrm{~cm}^{-1}<v_{\mathrm{CO}}<1,900 \mathrm{~cm}^{-1}$ ), where threefold species disappear at high temperatures with increasing reaction rate (Fig. 18a). Probably one of the most important aspects of the vibrational features of adsorbed $\mathrm{CO}$ given in Fig. 19 is the fact that all of these frequencies match with
$\mathrm{CO}$ molecules adsorbed on a metallic Rh surface and not with $\mathrm{RhO}_{x}$, as $\mathrm{CO}$ adsorption frequencies on oxidized $\mathrm{Rh}$ surfaces are expected to appear at much higher frequencies (e.g. $2,130 \mathrm{~cm}^{-1}$ ). Interpretation of the spectroscopic data in Fig. 19 together with the kinetic results presented in Fig. 18a suggests that for low reaction rate (CO-inhibited) regime, $\mathrm{CO}$ exists predominantly in atop configuration whose vibrational frequency red shifts down to $\sim 2,065 \mathrm{~cm}^{-1}$ with increasing temperatures/increasing reaction rates. Upon reaching the roll-over (i.e. steady state exhibiting a surface oxygen coverage higher than $0.5 \mathrm{ML}$ ), a new atop $\mathrm{CO}$ feature appears at $2,084 \mathrm{~cm}^{-1}$. This latter feature was attributed to the $\mathrm{CO}$ adsorbed on an O-rich metallic $\mathrm{Rh}(111)$ surface which is comprised of chemisorbed atomic oxygen species on metallic $\mathrm{Rh}(111)$, rather than a surface or a bulk rhodium oxide.

Gao et al. [82] also demonstrated that under extremely O-rich conditions (i.e. $\mathrm{O}_{2} / \mathrm{CO}=8 / 1$ ) at $460 \mathrm{~K}$, metallic $\mathrm{Rh}$ (111) surface can be oxidized after a certain time period under the reaction conditions which is accompanied by a drastic fall in the reaction rate and concomitant appearance of a new $\mathrm{CO}$ adsorption feature at $2,130 \mathrm{~cm}^{-1}$ associated with the atop $\mathrm{CO}$ adsorption on the oxide. Thus, these authors argued that neither bulk oxide nor surface oxides of $\mathrm{Rh}$ are active in $\mathrm{CO}$ oxidation reaction and the reaction is governed by simple Langmuir-Hinshelwood mechanism under steady state conditions where the active phase is comprised of O-rich $\left(\theta_{\mathrm{CO}}>0.5 \mathrm{ML}\right)$ metallic $\mathrm{Rh}(111)$ surface. Although interpretation of the experimental results of Goodman et al. summarized above seems to be selfconsistent, these results were recently challenged by highpressure surface X-ray diffraction (SXRD) results by (a)

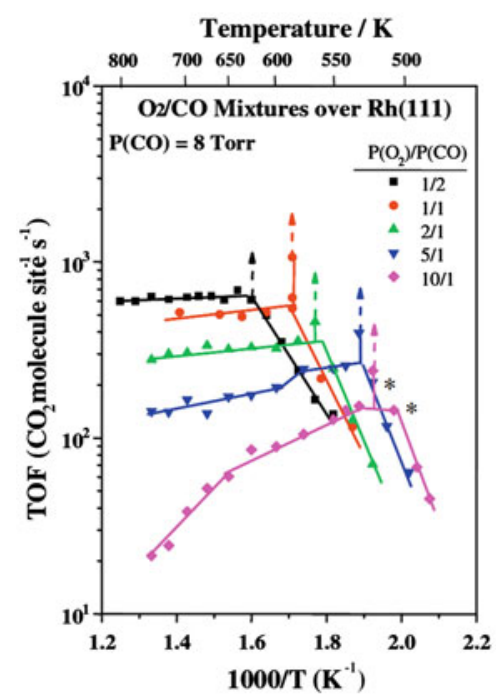

(b)

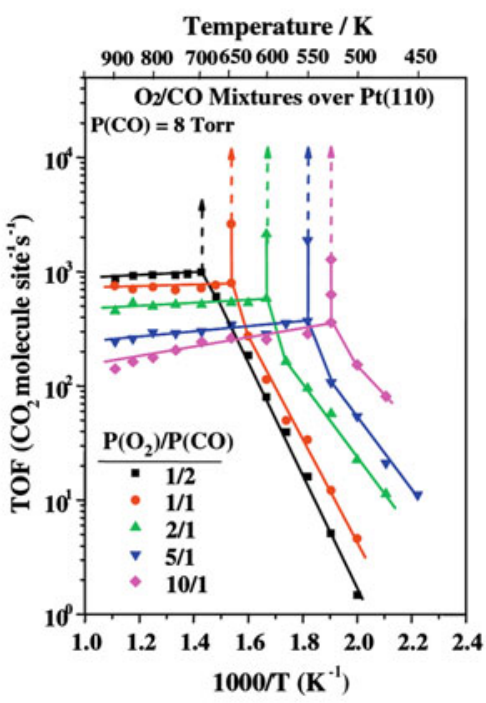

(c)

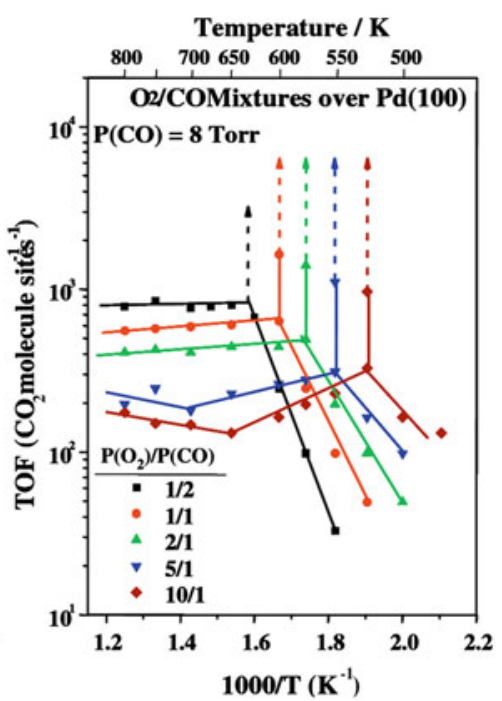

Fig. $18 \mathrm{CO}_{2}$ turn over frequency (TOF) values for $\mathrm{CO}+\mathrm{O}_{2}$ reaction on a $\mathrm{Rh}(111), \mathbf{b} \mathrm{Pt}(110)$ and $\mathbf{c} \mathrm{Pd}(100)$ at various temperatures and reactant compositions where partial pressure of $\mathrm{CO}$ is kept constant at 8 Torr $[83,88]$ 
Fig. $19 \mathrm{CO}+\mathrm{O}_{2}$ reaction on $\mathrm{Rh}(111)$ at various temperatures via PM-IRAS as a function of reactant compositions where partial pressure of $\mathrm{CO}$ is kept constant at 8 Torr. a $\mathrm{O}_{2} /$ $\mathrm{CO}=1 / 2$ mixture (stoichiometric), $\mathbf{b} \mathrm{O}_{2} / \mathrm{CO}=2 / 1$ mixture (mildly excess in $\mathrm{O}_{2}$ ), c $\mathrm{O}_{2} / \mathrm{CO}=5 / 1$ mixture (moderately excess in $\mathrm{O}_{2}$ )and d $\mathrm{O}_{2} / \mathrm{CO}=10 / 1$ mixture (heavily excess in $\mathrm{O}_{2}$ ) [82]
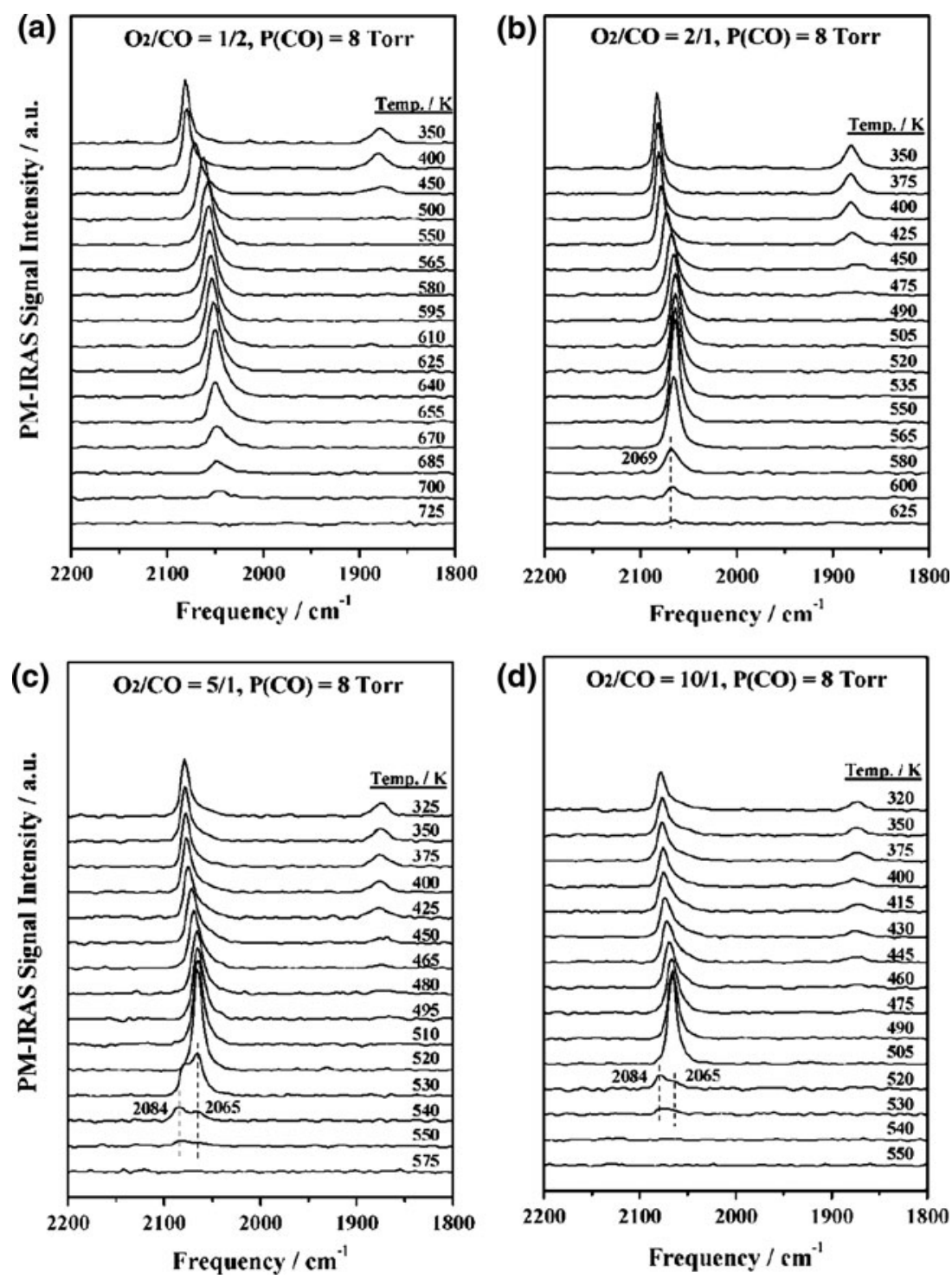

Gustafson et al. [91, 92] who argued that contribution from a "surface oxide" phase of rhodium to the high reaction rate should not be excluded.

\subsubsection{CO Oxidation on Pd(100) Similar PM-IRAS} (Fig. 20) and kinetic studies (Figs. 18c, 20b) on the CO oxidation reaction was also extended to $\mathrm{Pd}(100)$ model catalyst surfaces by Goodman and co-workers [87]. These authors reported that under the steady state reaction conditions at low pressures, $\mathrm{CO}$ oxidation reaction was found to be only $\mathrm{CO}$-inhibited without any sign of O-inhibition. Furthermore, under these conditions, CO conversion was found to be "collision-limited" and the optimized $\mathrm{CO}$ conversion is independent of the $\mathrm{O}_{2} / \mathrm{CO}$ for $\mathrm{P}_{\mathrm{CO}} \leq 1 \times 10^{-4}$ Torr, where the $\mathrm{CO}$ surface coverage was always extremely low [87]. On the other hand, under high pressures, three different reaction regimes were observed as in the case of $\mathrm{Rh}(111)$ [87]:(i) CO-inhibited low temperature regime with a low reaction rate, (ii) a MTL regime after the "roll-over" with a high reaction rate and (iii) a transient hyperactive (extremely fast) regime in between. PM-IRAS data given in Fig. 20a-d suggest that under the $\mathrm{CO}$-inhibited regime $\mathrm{CO}$ exhibits vibrational frequencies above $1,960 \mathrm{~cm}^{-1}$ corresponding to bridging $\mathrm{CO}$ with a surface coverage greater than 0.6 ML. For the stoichiometric (Fig. 20a) and mildly oxidizing (Fig. 20b) reactant mixtures, no $\mathrm{CO}$ species other than bridging $\mathrm{CO}$ was detected. Just after the roll-over, a steady state high reactivity regime is reached with $\theta_{\mathrm{CO}}$ close to zero. On the other hand a quite interesting behavior is observed for moderately/strongly $\mathrm{O}_{2}$-rich gas mixtures (Fig. 20c-e). For these $\mathrm{O}_{2}$-rich gas mixtures, in the $\mathrm{CO}$-inhibited regime (i.e. within 300-525 K), reaction rate increases with increasing temperature as a function of decreasing $\theta_{\mathrm{CO}}$ (Fig. 18c, e, region (i)). At $500-525 \mathrm{~K}$ the transient hyperactive state is reached (Fig. 18c, 20e, region (ii)) which has almost no 
adsorbed $\mathrm{CO}$ on the surface. However a further increase in temperature to $550 \mathrm{~K}$ results in a sharp fall in reaction rate (Fig. 18c, 20e, region (iii)) and the concomitant formation of two new features in PM-IRAS data at 2,087 and $2,142 \mathrm{~cm}^{-1}$ which were assigned to the $\mathrm{CO}$ adsorbed on 3D surface oxide (but not bulk PdO) formed on the $\mathrm{Pd}(100)$ model catalyst surface. This 3D surface oxide phase was argued to be a less reactive phase resulting in a decrease in the reaction rate below the MTL reaction rate (Fig. 18c). Increasing the temperature above $550 \mathrm{~K}$ leads to the disappearance of the 2,087 and $2,142 \mathrm{~cm}^{-1}$ features which is accompanied by an increase in the reaction rate back to MTL value, indicating the thermal decomposition of the inactive $\mathrm{PdO}_{x}$ surface oxide. Such arguments were also supported by other studies performed on high surface area (powder) $\mathrm{Pd} / \mathrm{Al}_{2} \mathrm{O}_{3}$ surfaces [99] favoring the active phase being the "O-covered metal surface" rather than the surface oxide. It is worth mentioning that Frenken and coworkers $[93,100]$ disagreed with these interpretations and claimed via SXRD experiments that the active phase in $\mathrm{CO}$ oxidation on $\operatorname{Pd}(100)$ is a surface oxide phase rather than the O-chemisorbed metallic $\mathrm{Pd}(100)$ surface.
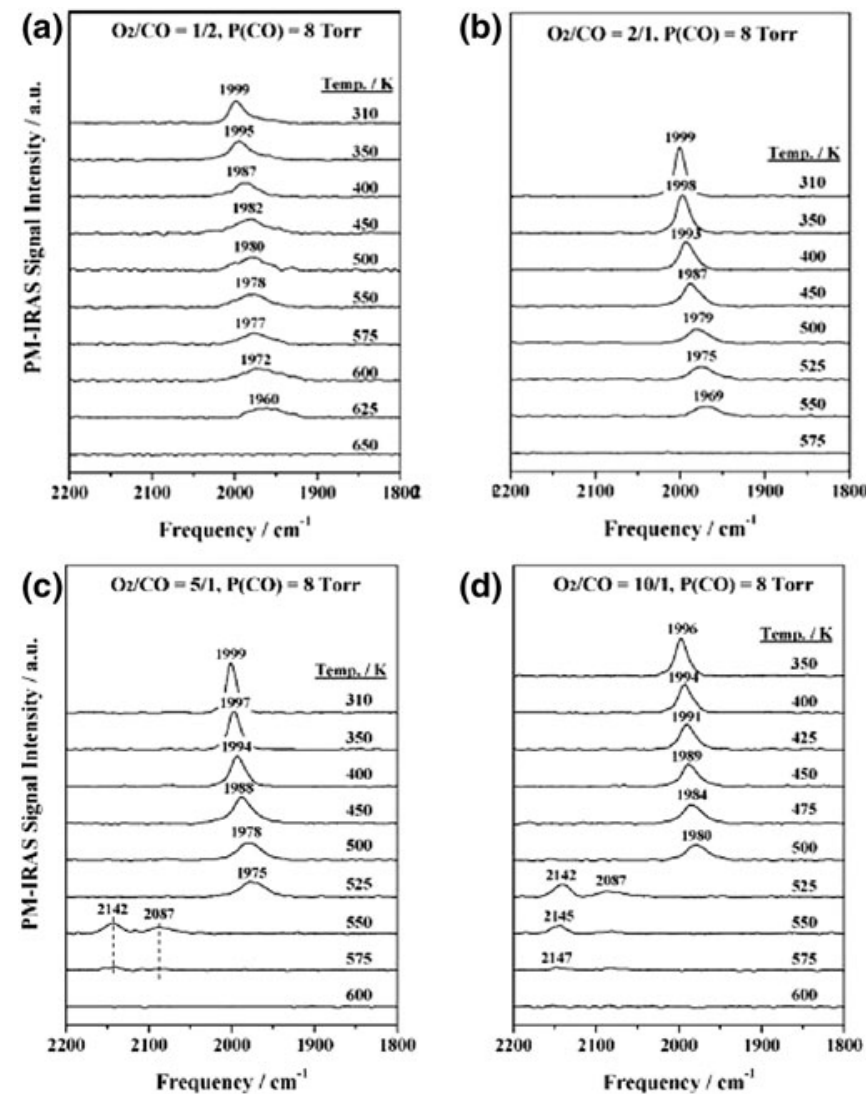

Fig. $20 \mathrm{CO}+\mathrm{O}_{2}$ reaction on $\mathrm{Pd}(100)$ at various temperatures via PM-IRAS as a function of reactant compositions where partial pressure of $\mathrm{CO}$ is kept constant at 8 Torr. a $\mathrm{O}_{2} / \mathrm{CO}=1 / 2$ mixture(stoichiometric), b $\mathrm{O}_{2} / \mathrm{CO}=2 / 1$ mixture (mildly excess in $\mathrm{O}_{2}$ ),
3.2.4.3 CO Oxidation on Pt(110) Analogous elevatedpressure $\mathrm{CO}$ oxidation reaction studies on $\mathrm{Pt}(110)$ by Goodman and co-workers [87] suggested that $\mathrm{Pt}(110)$ surface has similar CO-inhibited and hyperactive regimes which is followed by a roll-over leading to a high reactionrate (steady state) regime at elevated temperatures. Probably the most striking difference of the $\operatorname{Pt}(110)$ surface compared to $\mathrm{Pd}(100)$ and $\mathrm{Rh}(111)$ is the fact that even under extremely $\mathrm{O}_{2}$-rich gas mixtures (i.e. $\mathrm{O}_{2} / \mathrm{CO}=1 / 10$ ) no indications of Pt oxidation was observed via PM-IRAS. In other words, for all of the investigated gas compositions and temperatures, $\mathrm{CO}$ vibrational signal in PM-IRAS was found to be within $2,050-2,110 \mathrm{~cm}^{-1}$ and no $\mathrm{CO}$ vibrational signal above $2,110 \mathrm{~cm}^{-1}$ (a characteristic signature of oxide surfaces) was detected revealing the strong oxidation resistance of $\mathrm{Pt}(110)$ surface with respect to that of $\operatorname{Pd}(100)$ and $\operatorname{Rh}(111)$.

3.2.4.4 CO Oxidation on $\mathrm{Ru}(0001)$ and $\mathrm{RuO}_{2}$ As mentioned in earlier sections, Ru surfaces present an anomalous case in the $\mathrm{CO}$ oxidation reaction. In order to address this issue, Goodman and co-workers [83, 90] investigated the

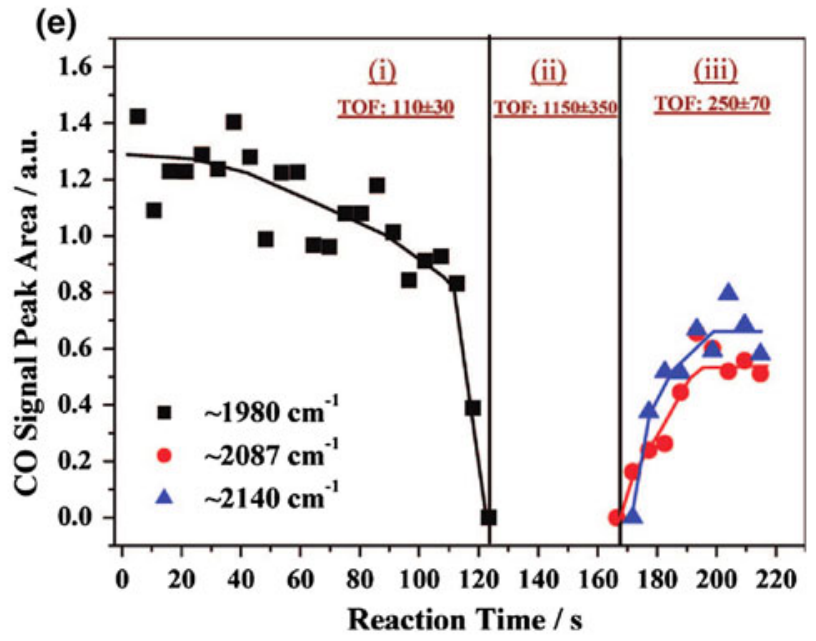

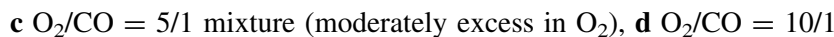
mixture (heavily excess in $\mathrm{O}_{2}$ ), e integrated $\mathrm{CO}$ signals at 1980, 2087 and $2140 \mathrm{~cm}^{-1}$ in PM-IRAS as a function of time for $\mathrm{a} \mathrm{O}_{2} / \mathrm{CO}=10 / 1$ mixture with $\mathrm{P}_{\mathrm{CO}}=2$ Torr at $500 \mathrm{~K}$ [87] 
behavior of the metallic $\left(\mathrm{Ru}(0001)\right.$ and oxide $\left(\mathrm{RuO}_{2}(110) /\right.$ $\mathrm{Ru}(0001))$ model catalyst surfaces using kinetic and spectroscopic techniques. These studies revealed that on $\mathrm{Ru}(0001)$, under stoichiometric and reducing conditions within $300-700 \mathrm{~K}$ as well as under net-oxidizing conditions below $475 \mathrm{~K}$, the most active phase was determined to be a metallic $\mathrm{Ru}(0001)$ surface which was covered with chemisorbed oxygen. This chemisorbed oxygen was also found to be thermodynamically stable phase, which can readily exist under these reaction conditions, where the $\mathrm{CO}$ oxidation reaction was reported to occur predominantly on the surface defect sites of the $(1 \times 1)-\mathrm{O} / \mathrm{Ru}(0001)$. The density of these sites was reported to be between $0.01-1 \times$ $10^{-5} \mathrm{ML}$, while the $\mathrm{CO}$ adsorption energy on these sites (i.e. $68 \mathrm{~kJ} / \mathrm{mol}$ ) is significantly lower than that of the O-covered $\mathrm{Pd}$, Pt and $\mathrm{Rh}$ (i.e. $\sim 100 \mathrm{~kJ} / \mathrm{mol}$ ) and $\mathrm{RuO}_{2}$ (i.e. $\sim 120 \mathrm{~kJ} / \mathrm{mol}$ ) [83, 90]. On the other hand, $\mathrm{RuO}_{2}(110) /$ $\mathrm{Ru}(0001)$ model catalyst prepared by growing an oxide ultrathin film on the metallic $\mathrm{Ru}(0001)$ substrate, was active and stable only at temperatures above $475 \mathrm{~K}$ and under net-oxidizing conditions. Furthermore, it was also pointed out that pure $\mathrm{RuO}_{2}$ in the absence of a metal substrate and strong metal support interaction or "SMSI" was not active. It was also demonstrated that for a stoichiometric gas mixture, the oxide ultrathin film on the $\mathrm{RuO}_{2}(110) / \mathrm{Ru}(0001)$ model catalyst surface was readily reduced to the metallic O-covered state (active phase).

On the other hand, under net-oxidizing conditions (i.e. $\left.\mathrm{O}_{2} / \mathrm{CO}=5 / 1\right)$ and at $550 \mathrm{~K},(1 \times 1)-\mathrm{O} / \mathrm{Ru}(0001)$ surface was observed to transform into $\mathrm{RuO}_{2}(110) / \mathrm{Ru}(0001)$ where the oxide phase revealed 4 times higher conversion than the $(1 \times 1)-\mathrm{O} / \mathrm{Ru}(0001)$ surface $[83,90]$. However, Goodman and co-workers [83] emphasized that this observation should not be interpreted in a universal fashion in order to assign a higher activity for $\mathrm{RuO}_{2}$ than a metallic $\mathrm{Ru}$ surface; as $\mathrm{RuO}_{2}$ phase is not stable below $500 \mathrm{~K}$ under reaction conditions. Furthermore, when the activity of these two surfaces were compared in a "per-active site" basis, $(1 \times 1)-\mathrm{O} / \mathrm{Ru}(0001)$ surface where active sites were reported to be the defect sites with a surface coverage as low as $10^{-5} \mathrm{ML}$ seems to be more active than the $\mathrm{RuO}_{2}(110) / \mathrm{Ru}(0001)$ surface having active coordinatively unsaturated cus-Ru sites with a coverage of $10^{-1} \mathrm{ML}$ [83]. PM-IRAS experiments performed by these authors during the $\mathrm{CO}+\mathrm{O}_{2}$ reaction on $\mathrm{RuO}_{2}(110) / \mathrm{Ru}(0001)$ surface revealed that assignment of $\mathrm{CO}$ vibrational features were rather complex. It was reported that on this surface: (i), $v_{\mathrm{CO}}$ $\sim 2,050 \mathrm{~cm}^{-1}$ was assigned to $\mathrm{CO}$ on reduced metallic $\mathrm{Ru}$;(ii) $2,050 \mathrm{~cm}^{-1}<v_{\mathrm{CO}}<2,080 \mathrm{~cm}^{-1}$ was attributed to oxygen-covered metallic $\mathrm{Ru}$ with $\theta_{\mathrm{o} \text { (ads) }} \leq 0.5 \mathrm{ML}$; (iii) $v_{\mathrm{CO}}>2,080 \mathrm{~cm}^{-1}$ was associated with $\mathrm{CO}$ on metallic $\mathrm{Ru}$ having a high $\theta_{\mathrm{o}(\text { ads) }}$ or $\mathrm{RuO}_{2}$ or $\mathrm{RuO}_{x}$; while (iv) $v_{\mathrm{CO}}$ $\sim 2,130-2,140 / 2,060-2,080 \mathrm{~cm}^{-1}$ bands could also be assigned to ruthenium carbonyl species (i.e. $\mathrm{Ru}^{x+}(\mathrm{CO})_{y}$ ) [83].

\subsubsection{CO Oxidation on $\mathrm{Au}-\mathrm{Pd}$ Bimetallic Alloy Cata-} lysts In a recent set of interesting reports, Goodman and co-workers [67, 68] investigated the elevated pressure $\mathrm{CO}+\mathrm{O}_{2}$ reaction via $\mathrm{PM}-\mathrm{IRAS}$ on $\mathrm{Au}-\mathrm{Pd}$ bimetallic alloy catalysts in various forms such as bimetallic single crystals (AuPd(100)), bimetallic Au-Pd alloy thin films grown on $\mathrm{Mo}(110)$ [70] and bimetallic $\mathrm{Au}-\mathrm{Pd}$ alloy nanoparticles deposited on $\mathrm{TiO}_{2}$ ultrathin films grown on Mo(110) [70]. It was reported that at low pressures, alloying with $\mathrm{Au}$ leads to alterations in the electronic structure and the reaction activation energy as well as the formation of isolated $\mathrm{Pd}$ sites which are incapable of $\mathrm{O}_{2}$ dissociation revealing a relatively less active surface. However at elevated pressures, upon surface segregation of $\mathrm{Pd}$ and the formation of contiguous Pd sites, a high activity was observed (even at low temperatures). As a result of the lower $\mathrm{CO}$ adsorption strength on the $\mathrm{Au}-\mathrm{Pd}$ alloys, these systems show superior $\mathrm{CO}$ oxidation performance compared to pure Pd catalysts which exhibit severe CO-inhibition for stoichiometric mixtures at elevated pressures and low temperatures. On the other hand, under net-oxidizing conditions at elevated pressures, $\mathrm{Pd}$ reveals a higher initial activity than $\mathrm{Au}-\mathrm{Pd}$ bimetallic systems due to its higher $\mathrm{O}_{2}$ activation/dissociation capability. Owing to the low oxidation resistance of $\mathrm{Pd}$ catalysts, these surfaces quickly lose their $\mathrm{CO}$ oxidation activity under net oxidizing conditions while the $\mathrm{Au}-\mathrm{Pd}$ alloy systems can robustly sustain their metallic structure and catalytic performance under the same conditions [70]. Furthermore, bimetallic single crystals, bimetallic $\mathrm{Au}-\mathrm{Pd}$ alloy thin films grown on $\mathrm{Mo}(110)$ and bimetallic $\mathrm{Au}-\mathrm{Pd}$ alloy nanoparticles deposited on $\mathrm{TiO}_{2}$ ultrathin films grown on $\mathrm{Mo}(110)$ showed similar kinetic behavior highlighting the structure insensitivity of this reaction at elevated pressures [70]. These interesting studies suggest that $\mathrm{Au}-\mathrm{Pd}$ systems can be potentially used as highly active and extremely stable oxidation catalysts in many industrial applications.

\subsubsection{Methanol Adsorption and Reaction on Pd-Based Model Catalysts}

Methanol adsorption, decomposition/partial oxidation and methanol steam reforming (MSR) reactions have been extensively studied via SFG and PM-IRAS on different forms of Pd-containing model catalyst surfaces in the literature. For a detailed discussion of these model catalyst studies and other mechanistic aspects of these reactions, reader is referred to a recent review article by Bäumer et al. and references therein [101]. Some of the earlier and informative surface science studies on methanol adsorption 
Fig. 21 a PM-IRAS data for methanol decomposition (bottom spectrum) and methanol oxidation (top spectrum) on $\operatorname{Pd}(111)$ at elevated pressures. b Time dependent evolution of $\mathrm{CH}_{2} \mathrm{O}$ and $\mathrm{CH}_{x}$ species during the methanol decomposition reaction [104]
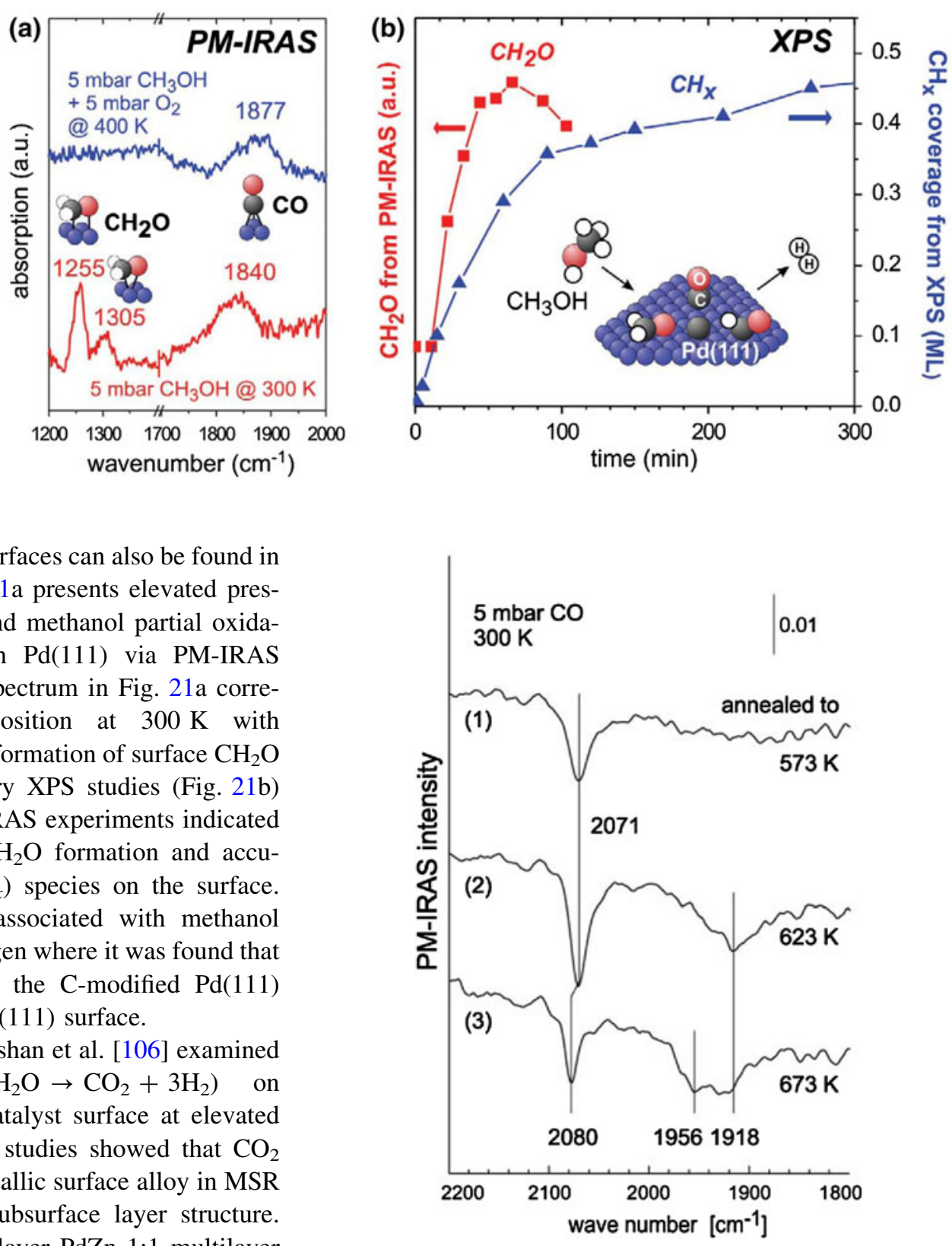

and reactions on single crystal surfaces can also be found in References [102, 103]. Figure 21a presents elevated pressure methanol decomposition and methanol partial oxidation experiments performed on $\mathrm{Pd}(111)$ via PM-IRAS technique [104, 105]. Bottom spectrum in Fig. 21a corresponds to methanol decomposition at $300 \mathrm{~K}$ with $\mathrm{P}_{\mathrm{MeOH}}=5$ mbar, revealing the formation of surface $\mathrm{CH}_{2} \mathrm{O}$ and $\mathrm{CO}$ species. Complementary XPS studies (Fig. 21b) performed along with the PM-IRAS experiments indicated a direct correlation between $\mathrm{CH}_{2} \mathrm{O}$ formation and accumulation of carbonaceous $\left(\mathrm{CH}_{x}\right)$ species on the surface. Top spectrum in Fig. 21a is associated with methanol oxidation in the presence of oxygen where it was found that the $\mathrm{CO}_{2}$ yield is enhanced on the C-modified $\mathrm{Pd}(111)$ surface, compared to a clean $\operatorname{Pd}(111)$ surface.

In a more recent study, Rameshan et al. [106] examined MSR reaction $\left(\mathrm{CH}_{3} \mathrm{OH}+\mathrm{H}_{2} \mathrm{O} \rightarrow \mathrm{CO}_{2}+3 \mathrm{H}_{2}\right)$ on $\mathrm{PdZn}(1: 1) / \operatorname{Pd}(111)$ bimetallic catalyst surface at elevated pressures via PM-IRAS. These studies showed that $\mathrm{CO}_{2}$ selectivity of the PdZn 1:1 bimetallic surface alloy in MSR reaction was dictated by the subsurface layer structure. Along these lines, while a five-layer PdZn 1:1 multilayer system revealed a high selectivity towards $\mathrm{CO}_{2} ; \mathrm{PdZn} \mathrm{1:1}$ monolayer surface produced exclusively $\mathrm{CO}$ and $\mathrm{H}_{2}$ rather than $\mathrm{CO}_{2}$. Furthermore using $\mathrm{CO}$ adsorption via PM-IRAS, variations in the surface composition of the bimetallic system at elevated temperatures and pressures were also monitored (Fig. 22). Top spectrum in Fig. 22 corresponds to $\mathrm{CO}$ adsorption on a multilayer PdZn (1:1) alloy annealed at $573 \mathrm{~K}$, exhibiting a homogenous surface composition, where $\mathrm{CO}$ adsorbs only in atop configuration $\left(2,071 \mathrm{~cm}^{-1}\right)$ due to the lack of contiguous Pd sites. Upon annealing the multilayer PdZn (1:1) alloy at $623 \mathrm{~K}$, complementary LEIS experiments suggested that the surface became richer in Pd. This is also evident in the corresponding PM-IRAS spectrum in Fig. 22 (middle spectrum) presenting the existence
Fig. 22 PM-IRAS data for 5 mbar $\mathrm{CO}$ adsorption at $300 \mathrm{~K}$ on a multilayer PdZn (1:1) alloy which is previously annealed at 573, 623 and $673 \mathrm{~K}$ [106]

of a new feature at $1,918 \mathrm{~cm}^{-1}$. Annealing at higher temperatures such as $673 \mathrm{~K}$ led to a further enrichment of the surface with $\mathrm{Pd}$ and the generation of a $1,956 \mathrm{~cm}^{-1} \mathrm{CO}$ vibrational signal associated with bridging $\mathrm{CO}$ on contiguous surface Pd sites [106].

\section{Conclusions and Outlook}

Monitoring the surface chemistry of heterogeneous catalysts under industrially relevant conditions such as elevated 
temperatures and pressures is a challenging yet an extremely rewarding task which requires dedicated in situ spectroscopy methods. Due to their photons-in, photonsout nature, vibrational spectroscopic techniques offer a very powerful and a versatile experimental tool box, allowing real-time investigation of working catalyst surfaces at elevated pressures. IRAS, polarization modulationIRAS (PM-IRAS or PM-IRRAS), SFG techniques reveal valuable surface chemical information at the molecular level, particularly when they are applied to atomically well-defined planar model catalyst surfaces such as single crystals or ultrathin films. In this review article, recent state of the art applications of in situ surface vibrational spectroscopy were presented with a particular focus on elevated pressure adsorption of probe molecules (e.g. $\mathrm{CO}, \mathrm{NO}, \mathrm{O}_{2}$, $\mathrm{H}_{2}, \mathrm{CH}_{3} \mathrm{OH}$,) on monometallic and bimetallic transition metal surfaces (e.g. Pt, Pd, Rh, Au, Co, PdZn, AuPd, CuPt). Furthermore, elevated pressure carbon monoxide oxidation, and $\mathrm{CO}$ hydrogenation, Fischer-Tropsch, methanol decomposition/partial oxidation and MSR reactions on single crystal PGM surfaces were discussed. Different case studies were discussed in order to demonstrate the capabilities, opportunities and the existing challenges associated with the in situ vibrational spectroscopic analysis of heterogeneous catalytic reactions on model catalyst surfaces at elevated pressures. These examples clearly indicate that although certain catalytic systems (e.g. CO/ $\operatorname{Pd}(111))$ lack a "pressure gap" where UHV experiments provide an excellent description of the catalytic system at elevated pressures, other simple model catalyst systems such as $\mathrm{NO} / \mathrm{Pd}(111)$ reveals a "pressure gap", where observation of various novel catalytic species becomes only possible under elevated temperatures and pressures. These case studies point to the fact that rather than relying solely on conventional UHV surface science experiments on model catalyst systems, in situ surface sensitive vibrational spectroscopic techniques such as PM-IRAS and SFG should be complemented with the conventional UHV methods in order to obtain a realistic and an accurate view of the working catalysts at the molecular level.

Acknowledgments E.O. acknowledges support from Turkish Academy of Sciences (TUBA) through the "Outstanding Young Investigator" Grant. E.V. acknowledges RFBR (Russia) \#12-0391373-CT_a for financial support.

\section{References}

1. Niemantsverdriet JW (2007) Spectroscopy in catalysis. VCH Verlagsgesellschaft $\mathrm{mbH}$, Weinheim

2. Ruppender HJ, Grunze M, Kong CW, Wilmers M (1990) Surf Interface Anal 15:245-253

3. Ogletree DF, Bluhm H, Lebedev G, Fadley CS, Hussain Z, Salmeron M (2002) Rev Sci Instrum 73:3872-3877
4. Pantforder J, Pollmann S, Zhu JF, Borgmann D, Denecke R, Steinruck HP (2005) Rev Sci Instrum 76:014102/1-014102/9

5. Laegsgaard E, Osterlund L, Thostrup P, Rasmussen PB, Stensgaard I, Besenbacher F (2001) Rev Sci Instrum 72: 3537-3542

6. Jensen JA, Rider KB, Chen Y, Salmeron M, Somorjai GA (1999) J Vac Sci Technol B 17:1080-1084

7. McIntyre BJ, Salmeron M, Somorjai GA (1993) Rev Sci Instrum 64:687-691

8. Rasmussen PB, Hendriksen BLM, Zeijlemaker H, Ficke HG, Frenken JWM (1998) Rev Sci Instrum 69:3879-3884

9. Gao F, Goodman DW (2012) Annu Rev Phys Chem 63:265-286

10. Hoffmann FM (1983) Surf Sci Rep 3:109-192

11. Chabal YJ (1988) Surf Sci Rep 8:211-357

12. Kunimatsu K, Golden WG, Seki H, Philpott MR (1985) Langmuir 1:245-250

13. Green MJ, Barner BJ, Corn RM (1991) Rev Sci Instrum 62:1426-1430

14. Barner BJ, Green MJ, Saez EI, Corn RM (1991) Anal Chem 63:55-60

15. Blaudez D, Buffeteau T, Cornut JC, Desbat B, Escafre N, Pezolet M, Turlet JM (1993) Appl Spectrosc 47:869-874

16. Faguy PW, Richmond WN, Jackson RS, Weibel SC, Ball G, Payer JH (1998) Appl Spectrosc 52:557-564

17. Ozensoy E (2004) Ph.D. Thesis. Texas A\&M University

18. Ozensoy E, Hess C, Goodman DW (2004) Top Catal 28:13-23

19. Ozensoy E, Meier DC, Goodman DW (2002) J Phys Chem B 106:9367-9371

20. Ozensoy E, Min BK, Goodman DW (2004) J Phys Chem B 108:4351-4357

21. Ozensoy E, Goodman DW (2004) Phys Chem Chem Phys 6:3765-3778 and references therein

22. Ozensoy E, Hess C, Loffreda D, Sautet S, Goodman DW (2005) J Phys Chem B 109:5414-5417

23. Hess C, Ozensoy E, Yi CW, Goodman DW (2006) J Am Chem Soc 128:2988-2994

24. Ozensoy E, Hess C, Goodman DW (2002) J Am Chem Soc 124:8524-8525 and references therein

25. Hess C, Ozensoy E, Goodman DW (2003) J Phys Chem B 107:2759-2764

26. Hess C, Ozensoy E, Goodman DW (2004) J Phys Chem B 108:14181-14182

27. Shen YR (1994) Surf Sci 299-300:551-562

28. Shen YR (1989) Nature 337:519-525

29. Rupprechter G (2007) Adv Catal 51:133-263

30. Vidal F, Tadjeddine A (2005) Rep Prog Phys 68:1095-1127

31. Lambert AG, Davies PB, Neivandt DJ (2005) Appl Spectrosc Rev 40:103-145

32. Moad AJ, Simpson GJ (2004) J Phys Chem B 108:3548-3562

33. Cremer PS, Somorjai GA (1995) J Chem Soc Faraday Trans 91:3671-3677

34. Cremer PS, Su XC, Shen YR, Somorjai GA (1996) J Am Chem Soc 118:2942-2949

35. Rupprechter G (2007) MRS Bull 32:1031-1037

36. Kuhn WK, Szanyi J, Goodman DW (1992) Surf Sci 274:L611L618

37. Stacchiola D, Thompson AW, Kaltchev M, Tysoe WT (2002) J Vac Sci Technol B 20:2101-2105

38. Rose MK, Mitsui T, Dunphy J, Borg A, Ogletree DF, Salmeron M, Sautet P (2002) Surf Sci 512:48-60

39. Unterhalt H, Rupprechter G, Freund HJ (2002) J Phys Chem B 106:356-367

40. Rupprechter G, Unterhalt H, Morkel M, Galletto P, Hu LJ, Freund HJ (2002) Surf Sci 502:109-122

41. Kaichev VV, Prosvirin IP, Bukhtiyarov VI, Unterhalt H, Rupprechter G, Freund HJ (2003) J Phys Chem B 107:3522-3527 
42. Rupprechter G, Kaichev VV, Unterhalt H, Morkel A, Bukhtiyarov VI (2004) Appl Surf Sci 235:26-31

43. Szanyi J, Kuhn WK, Goodman DW (1993) J Vac Sci Technol A 11:1969-1974

44. Goodman DW (1994) Surf Sci 299:837-848

45. Baumer M, Freund HJ (1999) Prog Surf Sci 61:127-198

46. Bowker M, Holroyd R, Perkins N, Bhantoo J, Counsell J, Carley A, Morgan C (2007) Surf Sci 601:3651-3660

47. Föttinger K, Schlögl R, Rupprechter G (2008) Chem Commun 0:320-322

48. Rupprechter G (2001) Phys Chem Chem Phys 3:4621-4632

49. Yudanov IV, Sahnoun R, Neyman KM, Rosch N, Hoffmann J, Schauermann S, Johanek V, Unterhalt H, Rupprechter G, Libuda J, Freund HJ (2003) J Phys Chem B 107:255-264

50. Dellwig T, Rupprechter G, Unterhalt H, Freund H-J (2000) Phys Rev Lett 85:776-779

51. Ertl G, Neumann M, Streit KM (1977) Surf Sci 64:393-410

52. Pedersen MO, Bocquet ML, Sautet P, Lægsgaard E, Stensgaard I, Besenbacher F (1999) Chem Phys Lett 299:403-409

53. Carrasco E, Aumer A, Brown MA, Dowler R, Palacio I, Song S, Sterrer M (2010) Surf Sci 604:1320-1325

54. Su X, Cremer PS, Shen YR, Somorjai GA (1996) Phys Rev Lett 77:3858-3860

55. Avery NR (1981) J Chem Phys 74:4202-4203

56. Andersson KJ, Chorkendorff I (2010) Surf Sci 604:1733-1736

57. Haruta M, Yamada N, Kobayashi T, Iijima S (1989) J Catal 115:301-309

58. Haruta M (2002) Cattech 6:102-115

59. Valden M, Lai X, Goodman DW (1998) Science 281:1647-1650

60. Gong J (2012) Chem Rev 112: 2987-3054 and references therein

61. Piccolo L, Loffreda D, Cadete Santos Aires FJ, Deranlot C, Jugnet Y, Sautet P, Bertolini JC (2004) Surf Sci 566-568:995-1000

62. Nakamura I, Takahashi A, Fujitani T (2009) Catal Lett 129:400-403

63. Artiglia L, Diemant T, Hartmann H, Bansmann J, Behm RJ, Gavioli G, Cavaliere E, Granozzi G (2010) Phys Chem Chem Phys 12:6864-6874

64. Gao F, Wood TE, Goodman DW (2010) Catal Lett 134:9-12

65. Paszti Z, Hakkel O, Keszthelyi T, Berko A, Balazs N, Bako I, Guczi L (2010) Langmuir 26:16312-16324

66. Diemant T, Hartmann H, Bansmann J, Behm RJ (2007) J Catal 252:171-177

67. Gao F, Wang Y, Goodman DW (2009) J Am Chem Soc 131:5734-5735

68. Gao F, Wang Y, Goodman DW (2009) J Phys Chem C 113:14993-15000

69. Gao F, Wang Y, Goodman DW (2009) J Catal 268:115-121 and references therein

70. Gao F, Wang Y, Goodman DW (2010) J Phys Chem C 114:4036-4043

71. Jugnet Y, Aires FJCS, Deranlot C, Piccolo L, Bertolini JC (2002) Surf Sci 521:L639-L644

72. Chen PJ, Goodman DW (1993) Surf Sci 297:L93-L99

73. Wallace WT, Cai Y, Chen MS, Goodman DW (2006) J Phys Chem B110:6245-6249

74. Jones JE, Trenary M (2008) J Phys Chem C 112:20443-20450

75. Németh R, Kiss J, Solymosi F (2007) J Phys Chem C 111:1424-1427

76. Solymosi F, Bansagi T, Zakar TS (2004) J Phys Chem B 108:14178-14180
77. Oosterbeek H (2007) Phys Chem Chem Phys 9:3570-3576

78. Beitel GA, de Groot CPM, Oosterbeek H, Wilson JH (1997) J Phys Chem B 101:4035-4043

79. Beitel GA, Laskov A, Oosterbeek H, Kuipers EW (1996) J Phys Chem 100:12494-12502

80. Morkel M, Rupprechter G, Hans-Joachim Freund HJ (2005) Surf Sci 588:L209-L219

81. Morkel M, Rupprechter G, Hans-Joachim Freund HJ (2003) J Chem Phys 119:10853-10866

82. Gao F, Cai Y, Gath K, Wang Y, Chen MS, Guo QL, Goodman DW (2009) J Phys Chem C 113:182-192

83. Gao F, Goodman DW (2012) Phys Chem Chem Phys 14:6688-6697 and references therein

84. Gao F, McClure S, Chen M, Goodman DW (2010) J Phys Chem C114:22369-22371

85. Gao F, Goodman DW (2010) Langmuir 26:16540-16551

86. McClure SM, Lundwall M, Yang F, Zhou Z, Goodman DW (2009) J Phys Chem C113:9688-9697

87. Gao F, Wang Y, Cai Y, Goodman DW (2009) J Phys Chem C 113:174-181

88. McClure SM, Goodman DW (2009) Chem Phys Lett 469:1-13 and references therein

89. Gao F, McClure SM, Cai Y, Gath KK, Wang Y, Chen MS, Guo QL, Goodman DW (2009) Surf Sci 603:65-70

90. Gao F, Wang Y, Cai Y, Goodman DW (2009) Surf Sci 603:1126-1134

91. Gustafson J, Westerstrom R, Balmes O, Resta A, van Rijn R, Torrelles X, Herbschleb CT, Frenken JWM, Lundgren E (2010) J Phys Chem C114:4580-4583

92. Gustafson J, Westerstrom R, Balmes O, Resta A, van Rijn R, Torrelles X, Herbschleb CT, Frenken JWM, Lundgren E (2010) J Phys Chem C 114:22372-22373

93. Rijn R, Balmes O, Felici R, Gustafson J, Wermeille D, Westerstrom R, Lundgren E, Frenken JWM (2010) J Phys Chem C 114:6875-6876

94. Dupont C, Loffreda D, Delbecq F, Aires FJCS, Ehret E, Jugnet Y (2008) J Phys Chem C 112:10862-19867

95. Dupont C, Delbecq F, Loffreda D, Jugnet Y (2011) J Catal 278:239-245

96. Sales BC, Turner JE, Maple MB (1982) Surf Sci 114:381-394

97. Ladas S, Imbihl R, Ertl G (1989) Surf Sci 219:88-106

98. Freund HJ, Meijer G, Scheffler M, Schlogl R, Wolf M (2011) Angew Chem Int Ed 50:10064-10094

99. Zorn K, Giorgio S, Halwax E, Henry CR, Gronbeck H, Rupprechter G (2011) J Phys Chem C 115:1103-1111

100. Gao F, Wang Y, Goodman DW (2010) J Phys Chem C 114:6874

101. Baumer M, Libuda J, Neyman KM, Rosch N, Rupprechter G, Freund HJ (2007) Phys Chem Chem Phys 9:3541-3558

102. Levis RJ, Jiang ZC, Winograd N (1989) J Am Chem Soc 111:4605-4612

103. Guo X, Hanley L, Yates JT (1989) J Am Chem Soc 111:3155-3157

104. Rupprechter G, Weilach C (2007) Nano Today 2:20-29

105. Borasio M, Fuente OR, Rupprechter G, Freund HJ (2005) J Phys Chem B 109:17791-17794

106. Rameshan C, Stadlmayr W, Weilach C, Penner S, Lorenz H, Havecker M, Blume R, Rocha T, Teschner D, Knop-Gericke A, Schlogl R, Memmel N, Zemlyanov D, Rupprechter G, Klotzer B (2010) Angew Chem Int Ed 49:3224-3227 and references therein 